\title{
Identification of a novel YAP-14-3-3ろ negative feedback loop in gastric cancer
}

\author{
Bin Zhang ${ }^{1}$, Aihua Gong ${ }^{1}$, Hui Shi ${ }^{1}$, Qingli Bie ${ }^{1}$, Zhaofeng Liang ${ }^{1}$, Peipei Wu ${ }^{1}$, Fei \\ Mao $^{1}$, Hui Qian ${ }^{1}$ and Wenrong $X \mathbf{u}^{1,2}$ \\ ${ }^{1}$ Key Laboratory of Laboratory Medicine of Jiangsu Province, School of Medicine, Jiangsu University, Zhenjiang, Jiangsu, P.R. \\ China \\ ${ }^{2}$ The Affiliated Hospital, Jiangsu University, Zhenjiang, Jiangsu, P.R. China \\ Correspondence to: Wenrong Xu email: icls@ujs.edu.cn \\ Hui Qian email: Istmmmlst@163.com
}

Keywords: YAP, 14-3-3ろ, MDM2, hippo, gastric cancer

Received: April 04, $2017 \quad$ Accepted: May 09, $2017 \quad$ Published: May 19, 2017

Copyright: Zhang et al. This is an open-access article distributed under the terms of the Creative Commons Attribution License 3.0 (CC BY 3.0), which permits unrestricted use, distribution, and reproduction in any medium, provided the original author and source are credited.

\section{ABSTRACT}

Growing evidence indicates that $14-3-3 \zeta$ and yes-associated protein (YAP) substantially promote tumorigenesis and tumor development. However, the regulatory mechanism underlying these two proteins remains unknown. Herein, we report a new regulatory role of 14-3-3 $\zeta$ in the phosphorylation of YAP and the feedback inhibition of 14-3-3 3 by YAP. YAP and 14-3-3 3 expression exhibited a negative correlation in gastric cancer (GC) tissues. Moreover, patients with higher YAP and lower 14-3-37 expression had poor prognoses. Studies have revealed that 14-3-3 cytoplasmic retention and suppresses the transcriptional activity of YAP by inducing its phosphorylation. Furthermore, we observed that the overexpression of YAP significantly reduced the expression of 14-3-3 $\zeta$ by inducing its ubiquitination. YAP, 14-3-3ろ, and mouse double minute 2 homolog (MDM2) were colocalized, and the knockdown of MDM2 by siRNA attenuated the YAP-induced decrease of 14-3-37. The binding of 14-3-3 $\zeta$ and MDM2 was also restrained when the expression of YAP was interfered. Our results indicated the presence of a 14-3-3Z-YAP negative regulatory feedback loop, which has a crucial role in cell proliferation and survival and is a potential target for the clinical treatment of GC.

\section{INTRODUCTION}

The incidence of gastric cancer (GC) has decreased over the past few decades; however, it remains the fourth most common cancer and second leading cause of death from cancer worldwide [1-3]. Over the past decades, considerable effort has been devoted to elucidating its underlying mechanisms and discovering novel diagnostic biomarkers and therapeutic targets. However, treatments for GC continue to be ineffective [4], and its mortality rate remains high [5]. Although extensive knowledge has been obtained regarding biomarkers and the therapeutic targets that affect cancer cell properties, few studies have investigated the role of mutual regulation among these proteins in GC or their underlying mechanisms.
The Hippo pathway plays a critical role in organ size control by regulating cell growth, proliferation, and apoptosis [6-9]. Yes-associated protein 1 (YAP) and transcriptional coactivator with PDZ-binding motif (TAZ) function as the key downstream effectors of the Hippo pathway [10]. In mammals, a key serine (S127) of YAP is phosphorylated by large tumor suppressor (LATS), which confines YAP within the cytoplasm where it can no longer target gene expression $[11,12]$. The abnormal activation of YAP, an oncoprotein, has been observed frequently in various cancer types [13-16]. YAP is also strongly expressed in gastric adenocarcinomas, and the knockdown of YAP may inhibit GC cell proliferation [17]. These findings reveal that the inhibitory molecules of YAP may be effective therapeutic targets in GC. 
The 14-3-3 protein family is expressed in various organs and is highly conserved in all eukaryotic organisms; it has seven different 14-3-3 isoforms in humans $[18,19]$. All 14-3-3 proteins can activate or inhibit the activity of target proteins by changing the protein conformation, increasing or decreasing protein stability, facilitating protein complex formation, or altering protein subcellular localization $[20,21]$. In recent years, the role of 14-3-3 proteins in malignant tumors has been increasingly reported. For example, 14-3-3 $\zeta$ was observed to be upregulated in prostate cancer and facilitate the progression of prostate cancer [22]. Furthermore, 14-3-3 $\zeta$ overexpression was found to be involved in PI3K triggered AKT phosphorylation and the cancer cell invasion in human breast cancer caused by ionizing radiation $[23,24]$.

A recent study reported that $14-3-3 \zeta$ can accelerate the progression of breast cancer by changing the function of TGF- $\beta$ [25]. The aforementioned studies have confirmed the facilitating role of $14-3-3 \zeta$ in prostate and breast cancers. Moreover, recent studies reporting the function of 14-3-3 proteins in the Hippo pathway have revealed that they bind to p127-YAP and induce YAP cytoplasmic retention [26, 27]. A recent study reported that 14-3-3 $\sigma$ can inhibit keratinocyte proliferation and promote differentiation by inducing YAP cellular localization [28]. Our results also confirmed that exosomal 14-3-3 $\zeta$ restricted cell expansion due to YAP [29]. These studies have all indicated that 14-3-3 $\zeta$ may perform another role by modulating YAP in GC.

In this study, we observed a strong correlation between 14-3-3 $\zeta$ and YAP expression and a contrasting pattern in gastric tissues. According to the results of a GC tissue microarray, GC patients had poor prognoses if they displayed higher levels of YAP protein expression than of $14-3-3 \zeta$ expression. This result indicated a potential regulatory mechanism between $14-3-3 \zeta$ and YAP. The overexpression of YAP in gastric cells enhanced its proliferation; however, the same effect was not observed for 14-3-3 $\zeta$. Additional studies have revealed that 14-3-3 $\zeta$ induced YAP phosphorylation at the serine 127 (Ser127) site. YAP also induced the ubiquitination and degradation of $14-3-3 \zeta$ by mediating the binding of mouse double minute 2 homolog (MDM2; an E3 ubiquitin ligase) and 14-3-3 $\zeta$. Thus, a remarkable negative feedback loop between YAP and 14-3-3 $\zeta$ was identified in GC.

\section{RESULTS}

\section{YAP and 14-3-3 $\zeta$ exhibited contrasting expression patterns in GC tissues that correlated with patients' prognoses}

Our early results revealed that $14-3-3 \zeta$ promoted YAP phosphorylation and thus restricted cell proliferation [29]. This result strongly suggested that $14-3-3 \zeta$ is not only a companion molecule but also a regulator of the Hippo pathway. Considering the critical role of YAP in cancer, we hypothesized that a novel regulatory mechanism exists between $14-3-3 \zeta$ and YAP in GC. To validate our hypothesis, we detected 14-3-3 $\zeta$ and YAP in a sample of GC tissues through western blot analysis. YAP and 14-3-3 $\zeta$ exhibited contrasting expression patterns in the GC tissues (Figures 1A and Supplementary Figure 1A). We reexamined the expression of 14-3-3 $\zeta$ and YAP and confirmed the expression pattern through immunohistochemistry (Figure 1B). Furthermore, to confirm this finding and account for the heterogeneity within GC tissues, we detected 14-3-3 $\zeta$ and YAP expression in a GC tissue microarray. The grading of YAP and 14-3-3 $\zeta$ expression is shown in Supplementary Figure 1C, with low expression (grades 1 and 2), and high expression (grades 3 and 4). Statistical analysis of the tissue microarray revealed a significant correlation between YAP and 14-3-3 $\zeta$ expression (Figure 1C). As shown in the Kaplan-Meier survival graph (Figure 1D), regardless of the inherent gene expression level, GC patients with higher grades of YAP expression than of 143-3 $\zeta$ expression had poor prognoses, with a survival rate of approximately $40 \%$. By contrast, the survival rate of patients with GC who had low grades of YAP expression and high grades of 14-3-3 $\zeta$ expression was the highest (approximately 90\%; Figure 1D). Tables 1 and 2 show that the expression of YAP and 14-3-3 $\zeta$ were associated with tumor size ( $p=0.021$ and 0.044 , respectively). However, no significant differences were observed between YAP, 14$3-3 \zeta$.level and histological grade $(p=0.412$ and 0.383 , respectively) and $\mathrm{T}$ categories ( $p=0.425$ and 0.590 , respectively), gender ( $p=0.255$ and 0.949 , respectively), age $(p=0.205$ and 0.923$)$, lymph node metastasis ( $\mathrm{N}$ factor; $p=0.0 .097$ and 0.458 , respectively), or tumor node metastasis stages ( $p=0.886$ and 0.391 , respectively). These results indicate a contrasting expression pattern of YAP and 14-3-3 $\zeta$ and reveal a linear correlation in GC tissues that may affect the prognoses of patients with GC.

\section{YAP and 14-3-3 $\zeta$ expression had contrasting effects on GC cell proliferation}

Although several studies have reported that YAP plays a crucial role in GC and other malignant tumors [17, 26, 27], we attempted to confirm the action of YAP in GC in our system. Western blotting and immunohistochemistry indicated that YAP expression was significantly higher in GC tissues compared with that in adjacent tissues (Figure $2 \mathrm{~A}$ and $2 \mathrm{~B}$ ). YAP overexpression strongly promoted MGC803 and SGC-7901 cell colony-forming ability, which was replicated in MKN-45 and HGC-27 cells (Figure 2C and Supplementary Figure 2A). The knockdown of YAP suppressed the colony-forming ability of HGC-27 and MGC-803 cells (Figure 2D). However, the overexpression of YAP did not promote the migration ability of MGC803 cells (Supplementary Figure 2C). Before performing 
these experiments, we validated the efficiency of YAP overexpression and knockdown (Figure 2E). These results indicated that YAP promoted GC cell proliferation and that high YAP expression in GC tissues is correlated with poor prognosis (Figure 2F).

Nishimura et al. reported that 14-3-3 $\zeta$ expression was high in GC tissues and was associated with tumor cell proliferation and the malignant outcomes of gastric carcinoma [30]. However, we observed that not all GC tissues expressed a high level of 14-3-3 $\zeta$. The expression

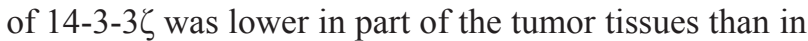
the normal gastric mucosa (Figure $3 \mathrm{~A}$ and $3 \mathrm{~B}$ ). To exclude the effects on our results of heterogeneity among GCs, we expanded the sample sizes by using a tissue microarray. The tissue microarray results indicated that only $50 \%$ of the GC tissue samples (89/178) exhibited higher 14-3-3 $\zeta$ expressions than those of adjacent tumor tissues (Figure 3C). This result was consistent with that reported by Nishimura et al. However, 14-3-3 $\zeta$ expression was low in $35.7 \%$ of GC tumor tissues (64/178; Figure 3C). More importantly, 14-3-3 $\zeta$ differed from YAP in that its low expression was correlated with poor prognosis (Figure 3D). In addition, 14-3-3 $\zeta$ overexpression markedly inhibited MGC-803 and SCG-7901 cell colony-forming ability (Figure 3E). This result was also confirmed in MKN-45 and HGC-27 cells (Supplementary Figure 3A). Similarly, 14-3-3 $\zeta$ did not inhibit the migration of MGC803 cells (Supplementary Figure 3B).

\section{4-3-3 $\zeta$ inhibited the activation of YAP by inducing its serine 127 phosphorylation and cytoplasmic retention}

Studies on the role of 14-3-3 proteins in the Hippo pathway have revealed that they bind to p127-YAP and induce the cytoplasmic retention of YAP $[9,10]$. However, Sambandam et al. were the first to demonstrate that the change of 14-3-3 expression can increase the cytoplasmic

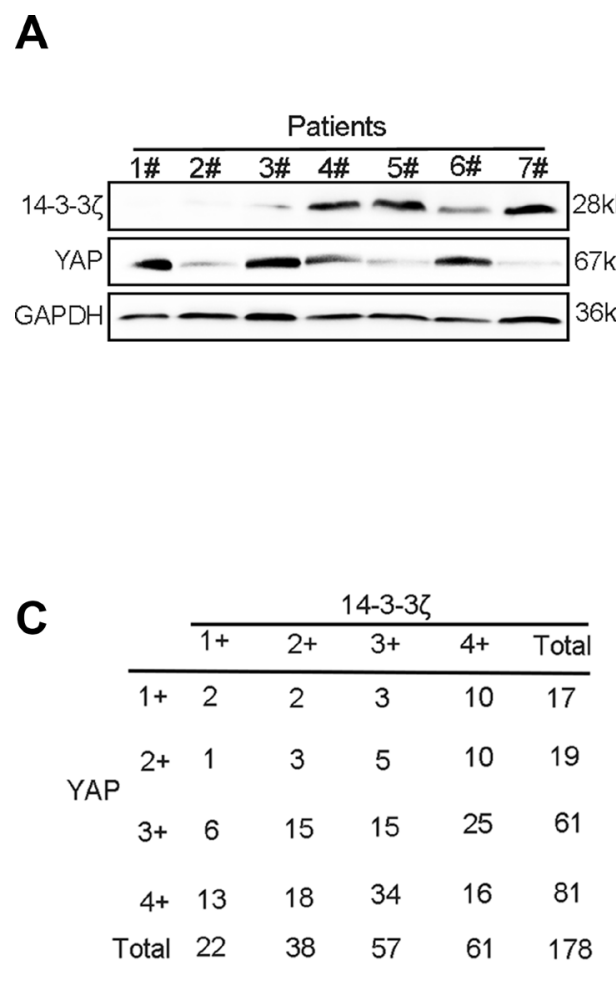

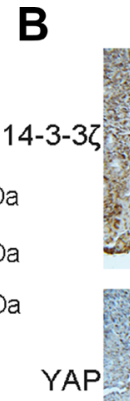

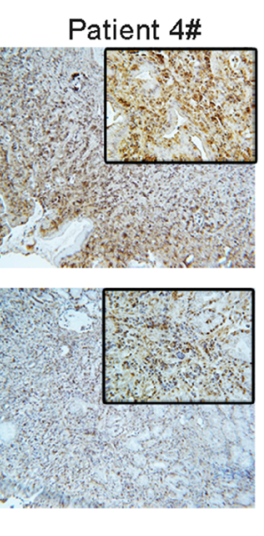

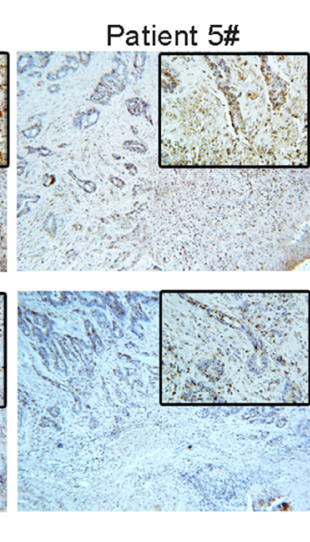

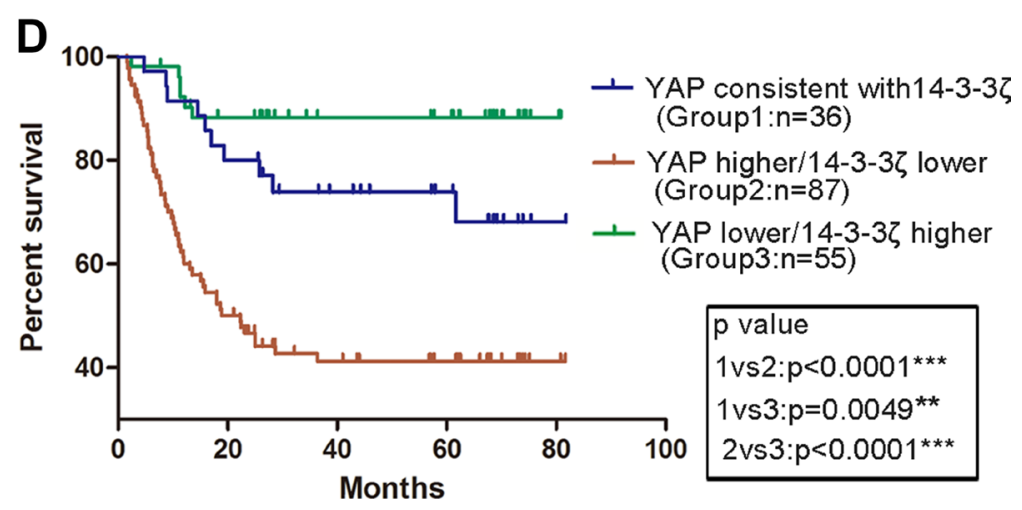

Figure 1: Contrasting expression patterns of YAP and 14-3-3 $\zeta$ in GC tissues were associated with patient prognoses.

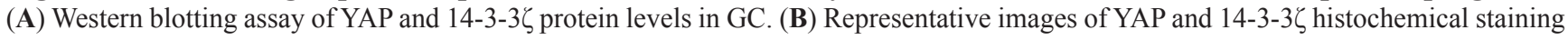
in surgical specimens from GC tissues. The patient numbers used in the immunohistochemistry analysis correspond to those used in the

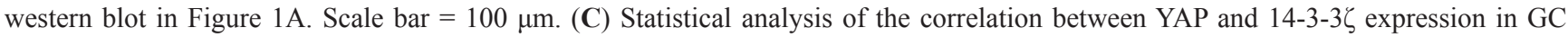

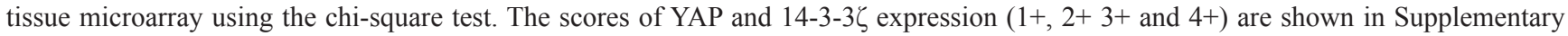
Figure 1A. (D) Kaplan-Meier analysis indicates a correlation between the cumulative survival and different expression patterns of YAP and 14-3-3 $\zeta$ among patients according to the results of GC tissue microarray. Statistical significance was assessed using the log-rank test. As

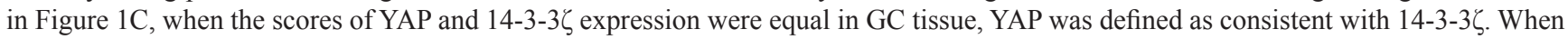
the score of YAP expression was higher than that of $14-3-3 \zeta$, it was defined as higher than 14-3-3 $\zeta$. When YAP expression score was lower than that of $14-3-3 \zeta$, it was defined as lower than $14-3-3 \zeta$. 


\begin{tabular}{|c|c|c|c|c|}
\hline \multirow{3}{*}{ Factor } & \multirow{3}{*}{ Number (\%) } & \multicolumn{2}{|c|}{ YAP IHC staining } & \multirow{3}{*}{$P$-value } \\
\hline & & Low & High & \\
\hline & & group & group & \\
\hline \multicolumn{5}{|l|}{ Age (years) } \\
\hline$>60$ & $81(45.5 \%)$ & 13 & 68 & 0.205 \\
\hline$\leq 60$ & $97(54.5 \%)$ & 23 & 74 & \\
\hline \multicolumn{5}{|l|}{ Gender } \\
\hline Male & $130(73 \%)$ & 29 & 101 & 0.255 \\
\hline Female & $48(27 \%)$ & 7 & 41 & \\
\hline \multicolumn{5}{|l|}{ Size $(\mathrm{cm})$} \\
\hline$>5$ & $85(47.8 \%)$ & 11 & 74 & $0.021^{*}$ \\
\hline$\leq 5$ & $93(52.2 \%)$ & 25 & 68 & \\
\hline \multicolumn{5}{|l|}{ Histological grade } \\
\hline Well + moderately & $75(42.1 \%)$ & 13 & 62 & 0.412 \\
\hline Poorly + signet & $103(57.9 \%)$ & 23 & 80 & \\
\hline \multicolumn{5}{|l|}{$\mathrm{T}$ grade } \\
\hline $\mathrm{T} 1+\mathrm{T} 2$ & $49(27.5 \%)$ & 8 & 41 & 0.425 \\
\hline $\mathrm{T} 3+\mathrm{T} 4$ & $129(72.5 \%)$ & 28 & 101 & \\
\hline \multicolumn{5}{|c|}{ Lymph node metastasis ( $\mathrm{N}$ factor) } \\
\hline Absent (N0) & $63(35.4 \%)$ & 17 & 46 & 0.097 \\
\hline Present (N1-N3) & $115(64.6 \%)$ & 19 & 96 & \\
\hline \multicolumn{5}{|l|}{ Stage } \\
\hline $\mathrm{I} / \mathrm{II}$ & $97(54.5 \%)$ & 20 & 77 & 0.886 \\
\hline III/IV & $81(45.5 \%)$ & 16 & 65 & \\
\hline
\end{tabular}

$* P<0.05$.

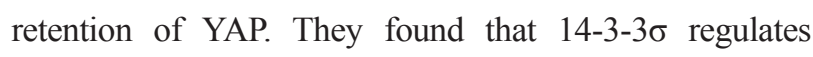
keratinocyte proliferation and differentiation by modulating YAP cellular localization [28]. We speculated that, as a 14-3-3 protein isoform, 14-3-3 3 may induce cytoplasmic retention through some novel mechanisms. As anticipated, 14-3-3 $\zeta$ overexpression promoted YAP translocation from the nucleus to the cytoplasm in SGC-7901 cells (Figure $4 \mathrm{~A}$ and $4 \mathrm{~B}$ ), and the knockdown of $14-3-3 \zeta$ reversed this phenomenon (Supplementary Figure 4A). Moreover, 14-3$3 \zeta$ overexpression suppressed the expression of the targets of YAP, namely CTGF and Cy61 in MGC-803 and SGC-7901 cells, respectively (Figure 4C and 4D), and the knockdown of 14-3-3 $\zeta$ promoted the expression of these targets (Figure 4E and $4 \mathrm{~F}$ ). The ability of YAP to promote the colony-forming ability of MGC-803 was enhanced by the knockdown of 14-3-3 (Figure 4G). In addition, the expansion indicators proliferating cell nuclear antigen (PCNA), cyclin-D1, and cyclin-D3 produced similar outcomes (Figure $4 \mathrm{H}$ and Supplementary Figure 4B). The expressions of CTGF and Cy61 were also enhanced by the shRNA lentivirus of 143-3 $\zeta$ (Figure $4 \mathrm{H}$ and $4 \mathrm{I}$ ). These results strongly suggested that $14-3-3 \zeta$ negatively regulated the nuclear translocation of YAP and its transcriptional activity.
Recent studies have revealed that the phosphorylation of the YAP-Ser127 site is the main mechanism of the cytoplasmic retention of YAP $[9,10]$. To determine the mechanism of action through which 14-3-3 $\zeta$ inhibits YAP, we detected the expression of YAP, p-YAP, 14-3-3 $\zeta$, and the YAP upstream kinase $p$-LATS1 in five GC cell lines with different degrees of differentiation. The results revealed that the phosphorylation of YAP at the Ser127 site was consistent with the trend of 143-3 $\zeta$ expression rather than that of p-LATS (Figure 4J). Consequently, we hypothesized that 14-3-3 $\zeta$ induces the phosphorylation of YAP at Ser127 to inhibit its activation. Both the overexpression and knockdown of 14-3-3 $\zeta$ validated our hypothesis; $14-3-3 \zeta$ affected the phosphorylation of YAP in MGC-803 and SGC-7901 cells (Figure $4 \mathrm{~K}-4 \mathrm{~N}$ ). The role of $\mathrm{p} 127-\mathrm{YAP}$ was further explored through site-directed mutagenesis. Notably, the mutation of Ser127 nearly supressed the inhibitory effect of 14-3-3 $\zeta$ on YAP transcriptional activity (Figure 4O). The phosphorylation of YAP induced by 14-3-3 $\zeta$ depended on LATS1, because the knockdown of LATS1 fully accounts for the phosphorylation of YAP due to $14-3-3 \zeta$

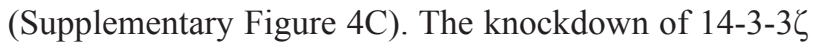


Table 2: Correlation between clinicopathological factors and 14-3-3 $\zeta$ IHC staining in GC samples

\begin{tabular}{|c|c|c|c|c|}
\hline \multirow{3}{*}{ Factor } & \multirow{3}{*}{ Number (\%) } & \multicolumn{2}{|c|}{ 14-3-3 $\zeta$ IHC staining } & \multirow{3}{*}{$P$-value } \\
\hline & & Low & High & \\
\hline & & group & group & \\
\hline \multicolumn{5}{|l|}{ Age (years) } \\
\hline$>60$ & $81(45.5 \%)$ & 27 & 54 & 0.923 \\
\hline$\leq 60$ & $97(54.5 \%)$ & 33 & 64 & \\
\hline \multicolumn{5}{|l|}{ Gender } \\
\hline Male & $130(73 \%)$ & 44 & 86 & 0.949 \\
\hline Female & $48(27 \%)$ & 16 & 32 & \\
\hline \multicolumn{5}{|l|}{ Size $(\mathrm{cm})$} \\
\hline$>5$ & $85(47.8 \%)$ & 35 & 50 & $0.044^{*}$ \\
\hline$\leq 5$ & $93(52.2 \%)$ & 25 & 68 & \\
\hline \multicolumn{5}{|l|}{ Histological grade } \\
\hline Well + moderately & $75(42.1 \%)$ & 28 & 47 & 0.383 \\
\hline Poorly + signet & $103(57.9 \%)$ & 32 & 71 & \\
\hline \multicolumn{5}{|l|}{$\mathrm{T}$ grade } \\
\hline $\mathrm{T} 1+\mathrm{T} 2$ & $49(27.5 \%)$ & 15 & 34 & 0.590 \\
\hline $\mathrm{T} 3+\mathrm{T} 4$ & $129(72.5 \%)$ & 45 & 84 & \\
\hline \multicolumn{5}{|c|}{ Lymph node metastasis( $\mathrm{N}$ factor $)$} \\
\hline Absent (N0) & $63(35.4 \%)$ & 19 & 44 & 0.458 \\
\hline Present (N1-N3) & $115(64.6 \%)$ & 41 & 74 & \\
\hline \multicolumn{5}{|l|}{ Stage } \\
\hline $\mathrm{I} / \mathrm{II}$ & $97(54.5 \%)$ & 30 & 67 & 0.391 \\
\hline III/IV & $81(45.5 \%)$ & 30 & 51 & \\
\hline
\end{tabular}

$* P<0.05$.

expression disturbed the interaction between YAP and pLATS1 in MGC-803 cells (Supplementary Figure 4D).

\section{YAP reduced the expression of 14-3-3}

We found that $14-3-3 \zeta$ induced the phosphorylation of YAP but did not inhibit its complete expression. In brief, the contrasting expression patterns of YAP and $14-3-3 \zeta$ in GC tissues required further elucidation. Because of these results, we suspected that the effect of YAP on 14-3-3 $\zeta$ expression involves a negative feedback loop. Therefore, we overexpressed YAP in 293T cells and found that YAP markedly reduced the expression of $14-3-3 \zeta$ in a concentration-dependent manner (Figure 5A). Although 14-3-3 $\sigma$ can regulate YAP in other cancer cells [31], the overexpression of YAP did not decrease other 14-3-3 proteins such as 14-3-3 $\eta, 14-3-3 \varepsilon, 14-3-3 \gamma$,

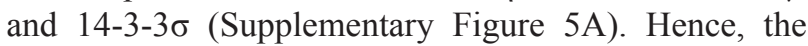
expressions of other 14-3-3 proteins including 14-3-3 $\sigma$ were not detected in GC tissue. The knockdown of YAP by shRNA promoted the expression of $14-3-3 \zeta$ in 293T cells (Figure 5B). This result was confirmed in BGC-823, MGC803, and MKN-45 cells (Figures 5C and Supplementary

Figure 5B). Moreover, immunofluorescence results revealed that YAP overexpression reduced 14-3-3 $\zeta$ expression in MGC-803, MKN-45, and BGC-823 cells (Figures 5D and Supplementary Figure 5C). Similarly, YAP downregulation promoted $14-3-3 \zeta$ expression in MGC-803 cells (Figure 5E).

\section{YAP recruited MDM2 to 14-3-3 $\zeta$ and induced the ubiquitination of 14-3-3 $\zeta$}

To explore the mechanism underlying the YAPinduced suppression of 14-3-3 $\zeta$ expression, we detected the mRNA level of $14-3-3 \zeta$ in 293T cells in which YAP was overexpressed or knocked down. YAP could not inhibit the expression of the 14-3-3 $\zeta$ mRNA level (Figure 6A and 6B), indicating that posttranslational regulation underlies the regulation of $14-3-3 \zeta$ by YAP. Shen et al. reported that YAP directly induced miRNA-130a expression to inhibit VGLL4 expression [32]. Therefore, we first hypothesized that YAP inhibits the expression of $14-3-3 \zeta$ by expressing microRNA (miRNA). We identified 12 miRNAs that can bind to the 3'-untranslated regions of $14-3-3 \zeta$ by using the TargetScan website (Supplementary Figure 6A). Only 
A
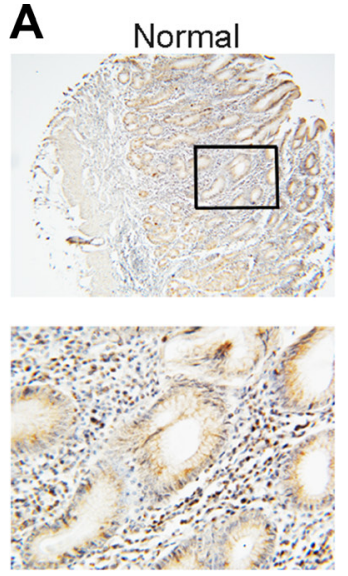

C
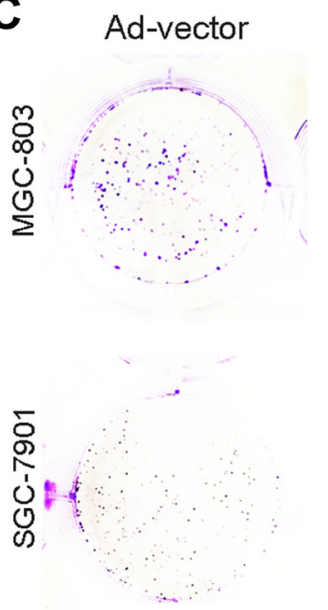

Tumor
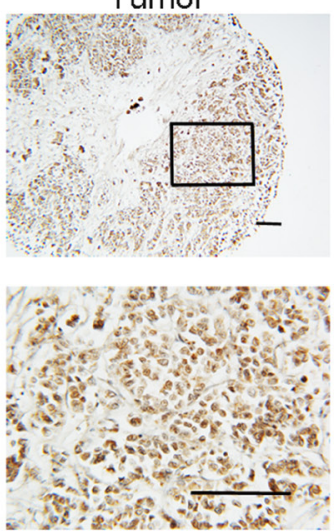

B
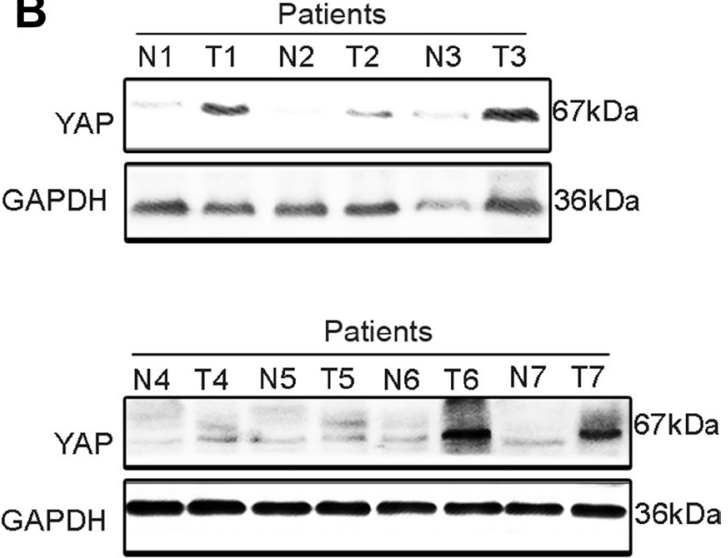

$\mathbf{E}$

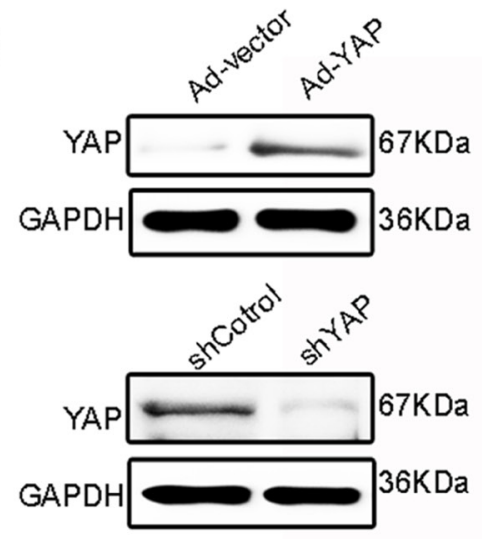

D shControl
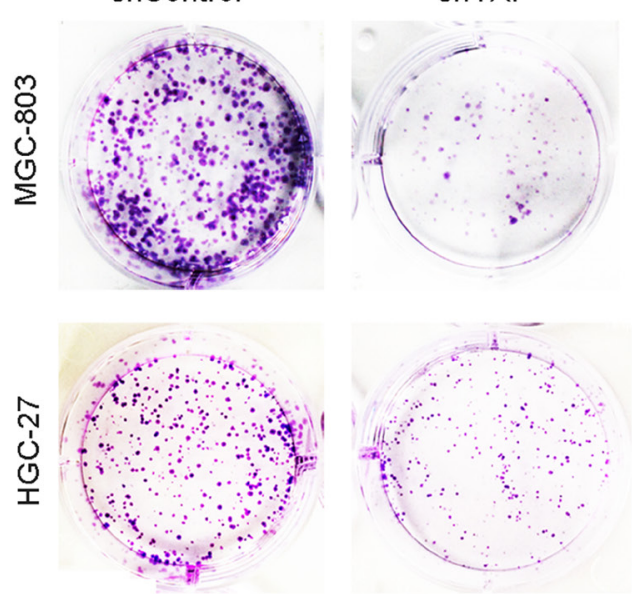

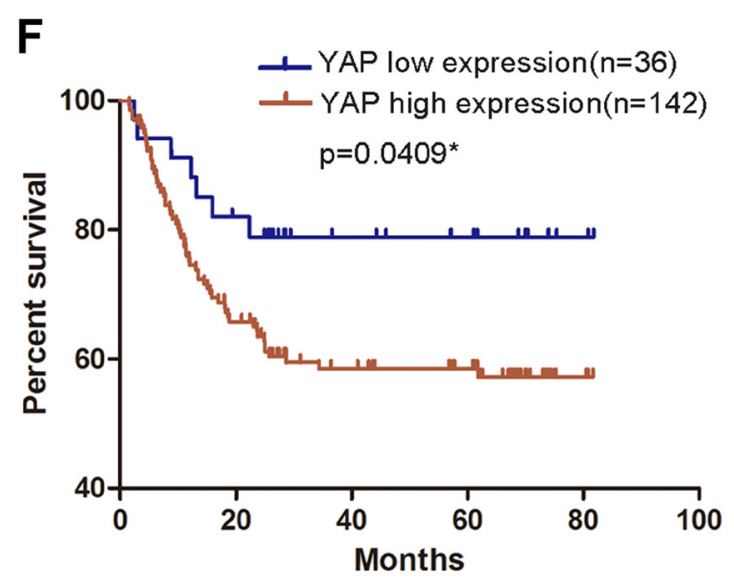

Figure 2: YAP expression in GC tissues and paired adjacent normal tissues and its proliferation-promoting role in GC cells. (A) Representative images of YAP histochemical staining in surgical specimens from normal and GC tissues. Scale bar $=100 \mu \mathrm{m}$. (B) Western blotting assay of YAP protein levels in GC (T) and corresponding adjacent tissues $(\mathrm{N})$. (C) Representative images of colony formation in blank vector (Ad-vector)- and YAP-overexpressing adenovirus (Ad-YAP)-transfected MGC-803 and SGC-7901 cells. The Ad-YAP and Ad-vector transfected cells were cultured for 5 days. (D) Representative images of colony formation in shYAP and shControl-transfected MGC-803 and HGC-27 cells. shYAP and shControl-transfected cells were cultured for 10 days. (E) Validation of the knockdown or overexpression effect in Figure 2C and 2D through western blotting. (F) The grading of YAP and 14-3-3 $\zeta$ expression is shown in Supplementary Figure 1B, with low expression (grades 1 and 2) and high expression (grades 3 and 4). Kaplan-Meier analysis shows a correlation between cumulative survival and YAP expression levels in patients with GC. Statistical significance was assessed using the log-rank test. 
A

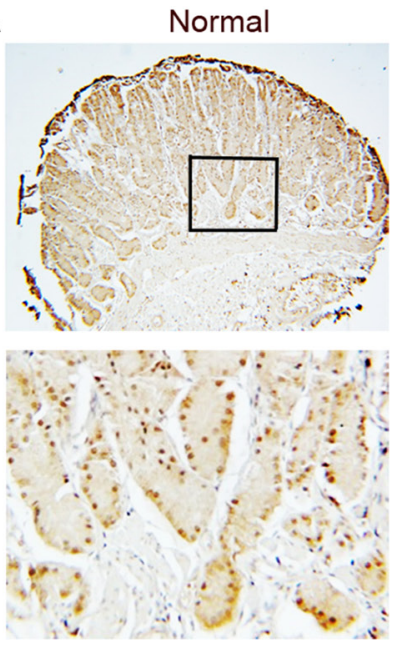

Tumor 1
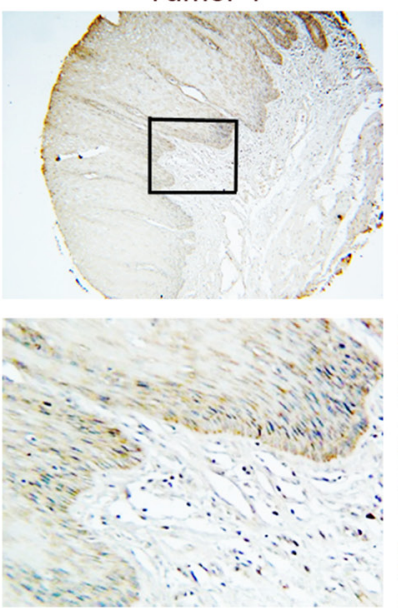

Tumor 2
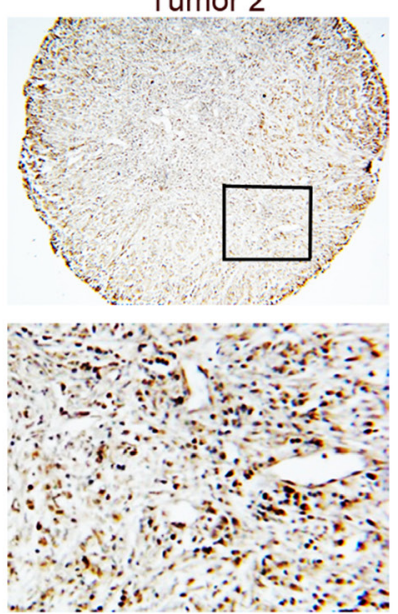

Tumor 3
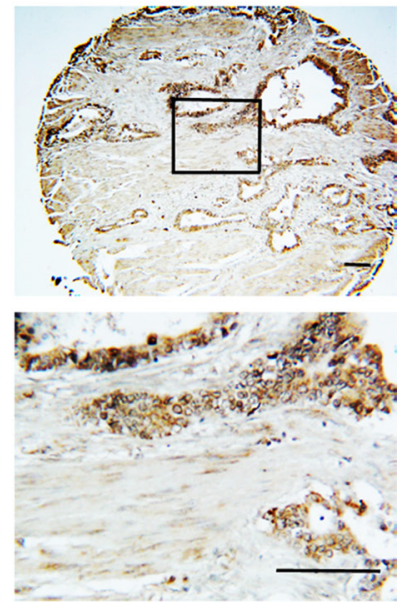

B
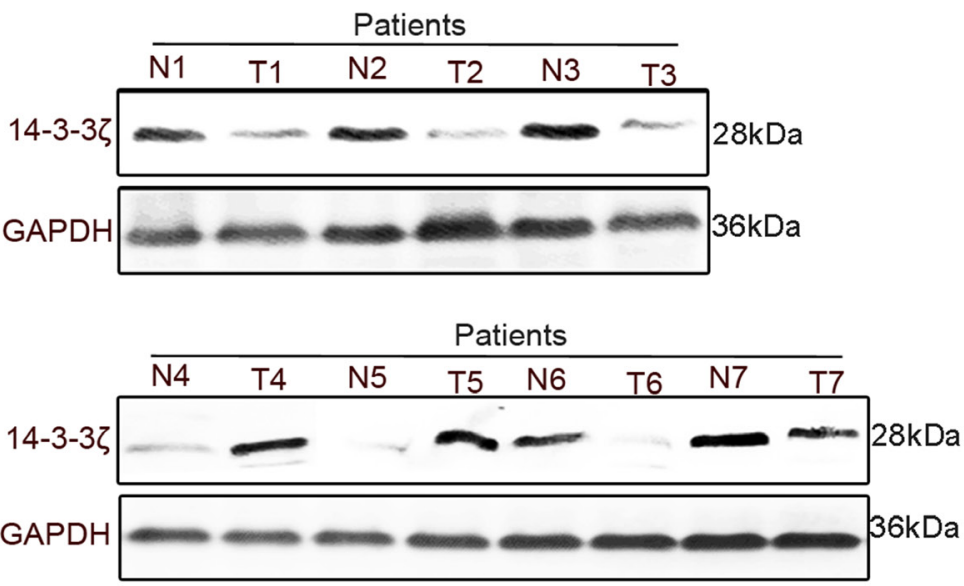

C

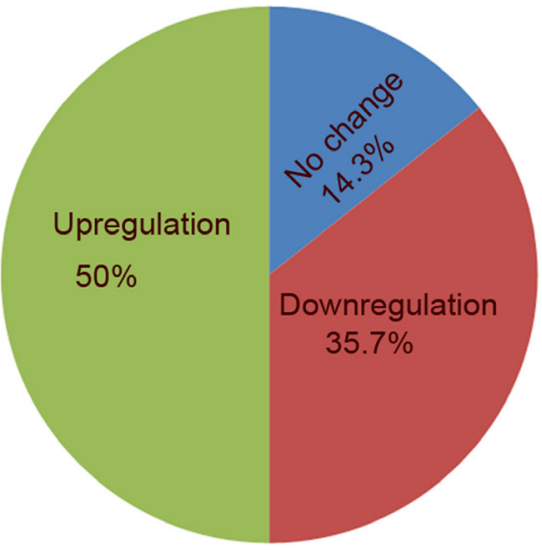

D

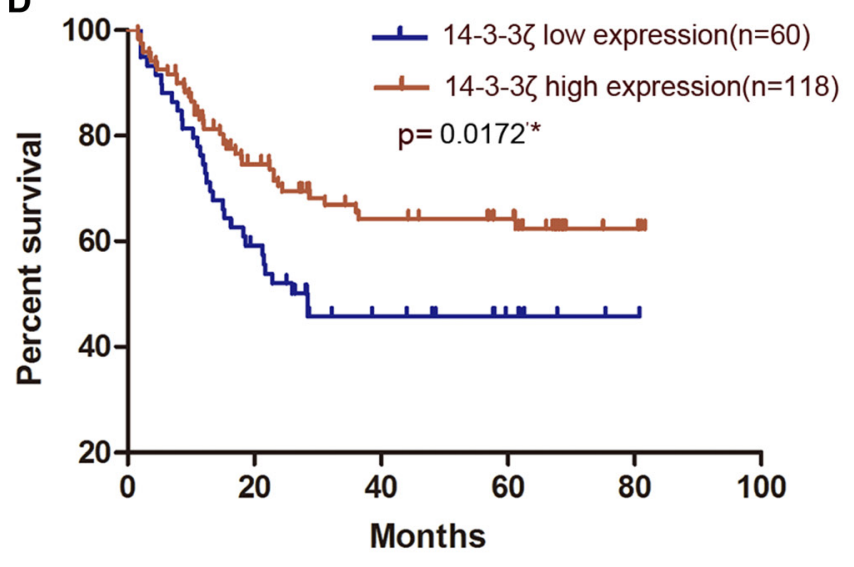

E

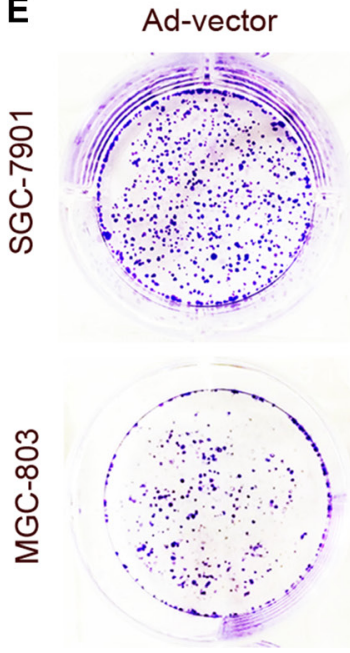

Ad-14-3-3ろ

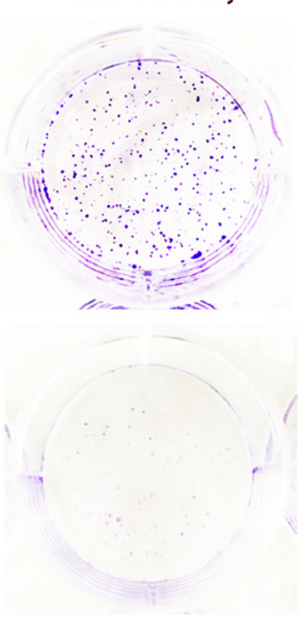

Figure 3: Expression of 14-3-3 $\zeta$ was detected in GC tissues and paired adjacent normal tissues and its role in GC

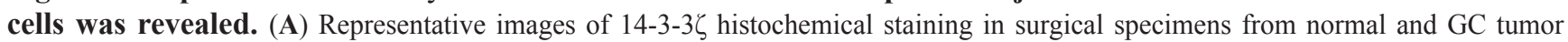

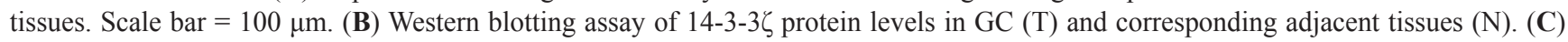

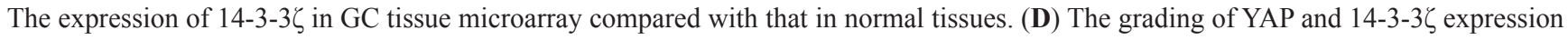
is shown in Supplementary Figure 1B, with low expression (grades 1 and 2), and high expression (grades 3 and 4). Kaplan-Meier analysis indicates a correlation between cumulative survival and 14-3-3 $\zeta$ expression levels in patients with GC. Statistical significance was assessed

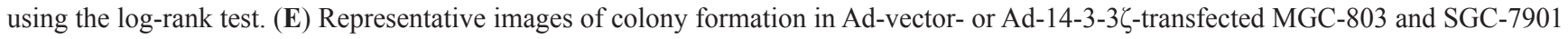
cells. The transfected cells were cultured for 5 days. 

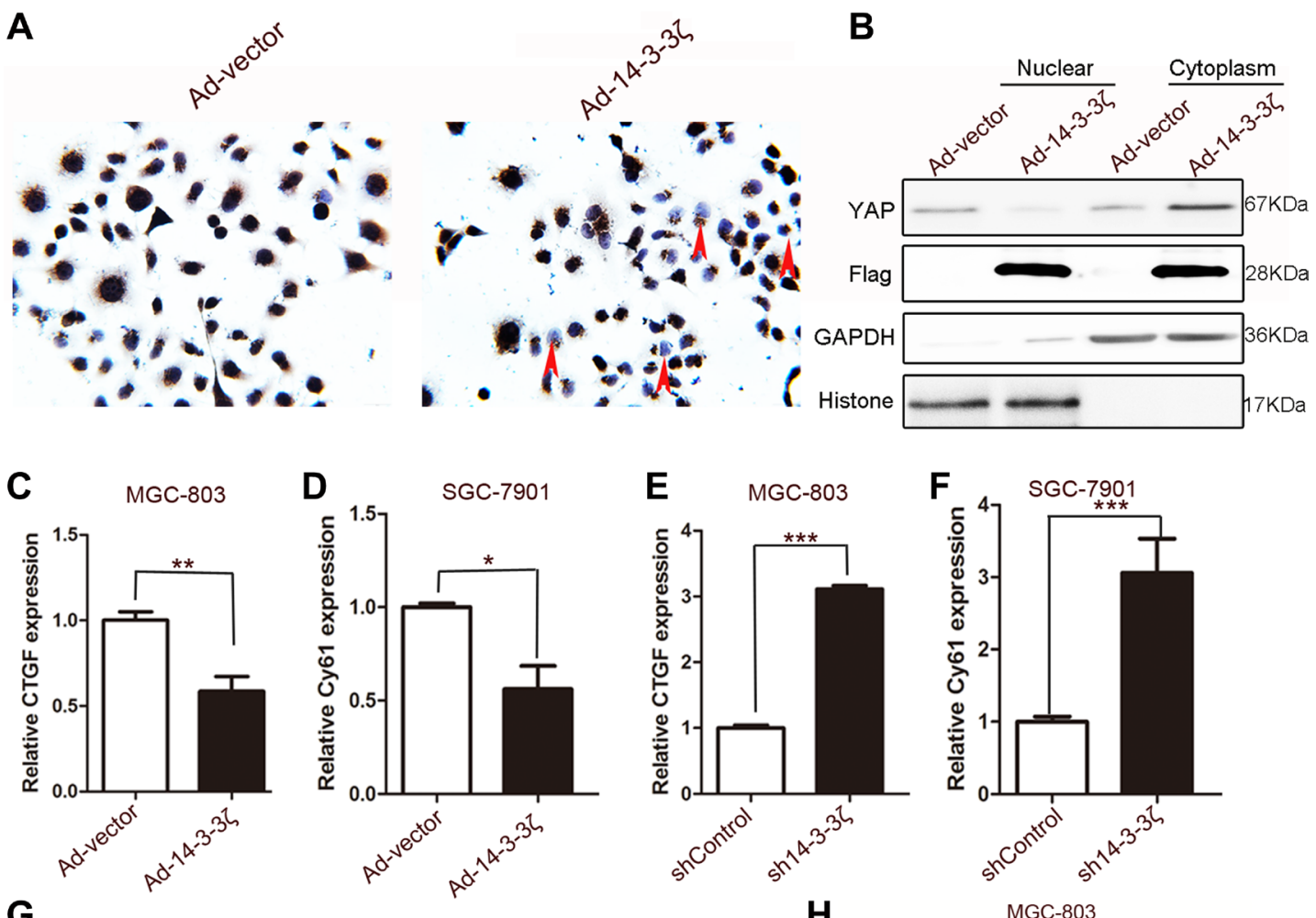

G
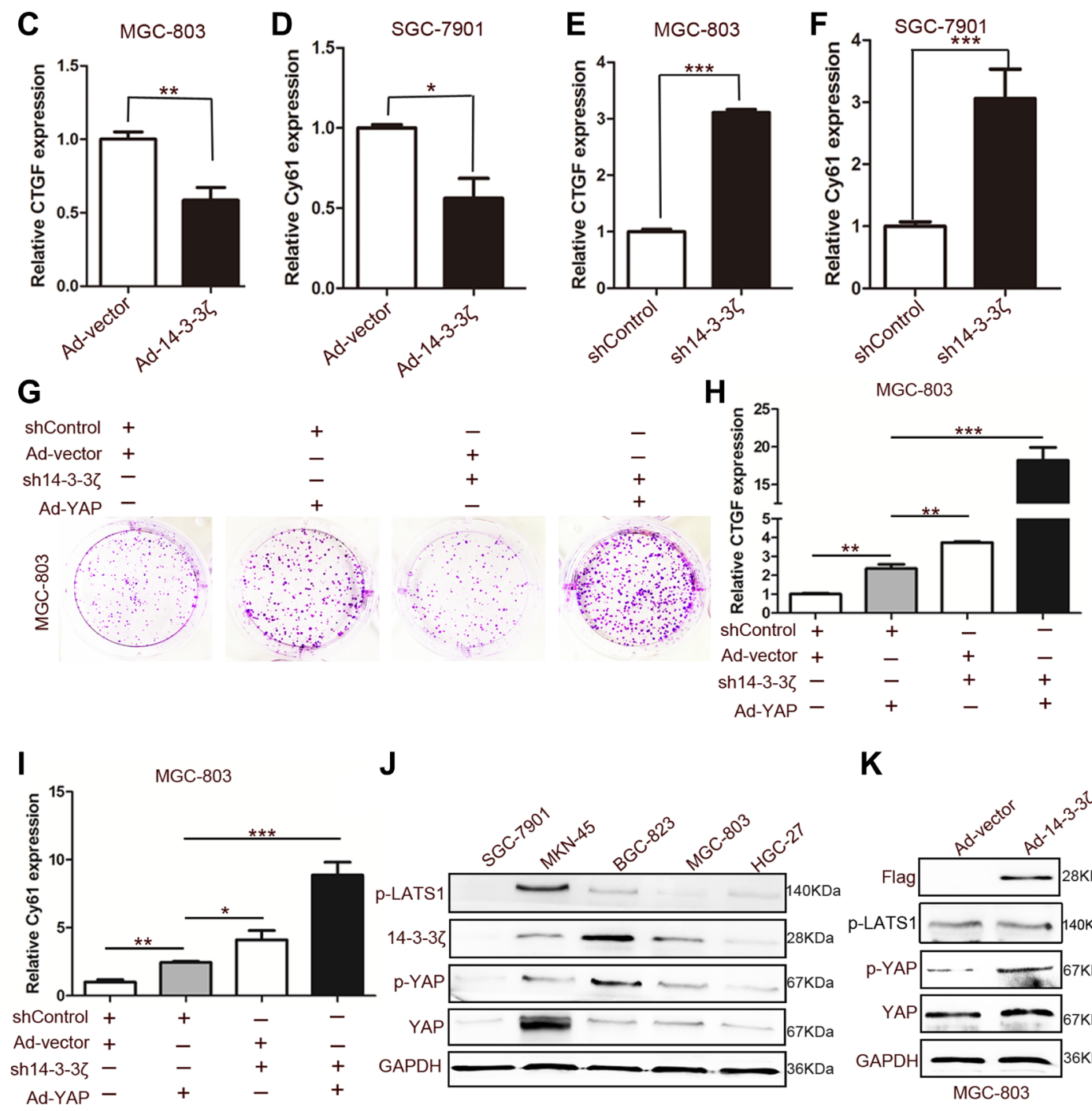

J
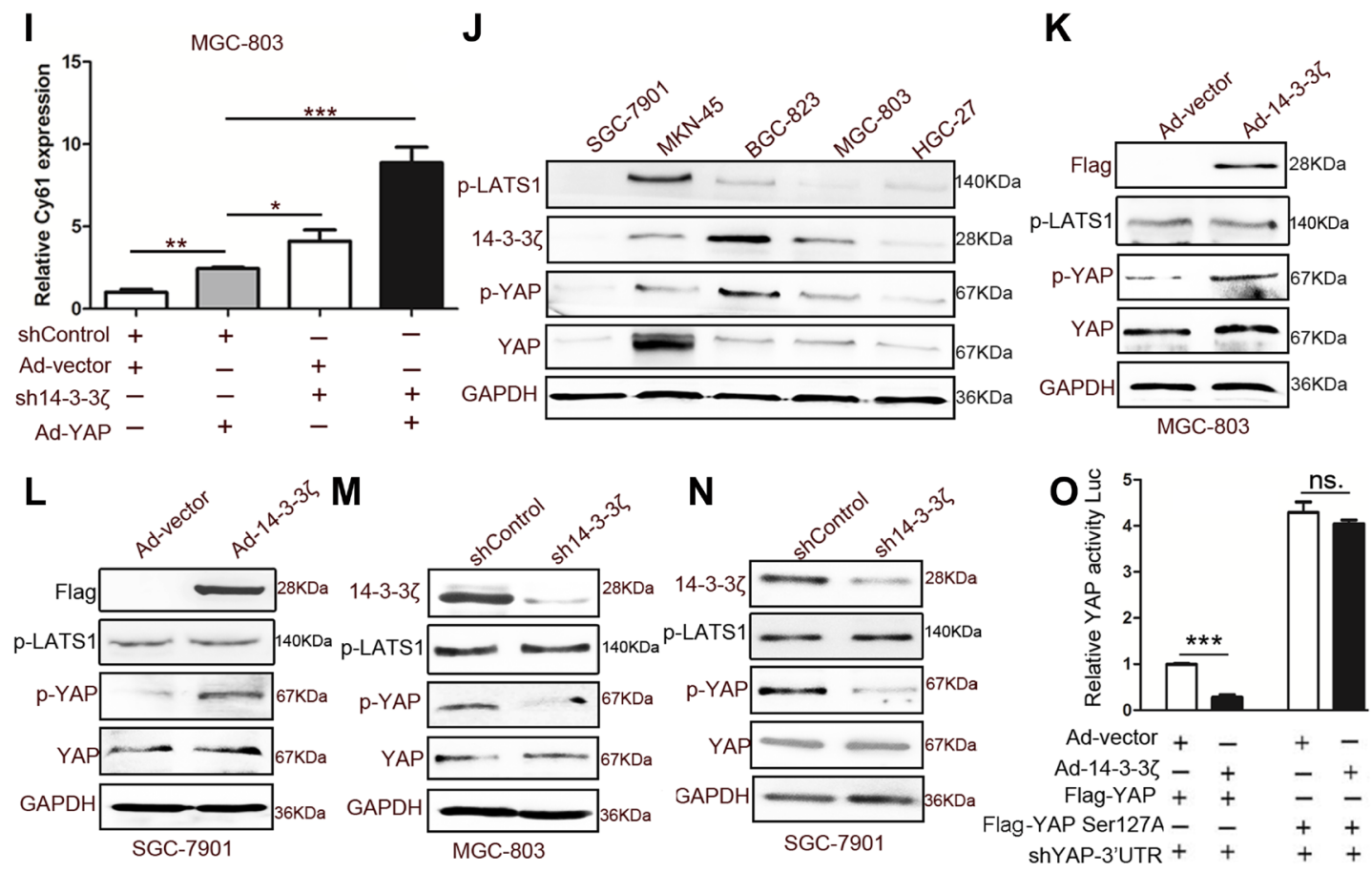


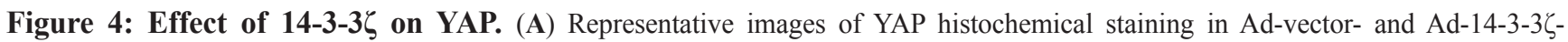
transfected MGC-803 cells. The red arrows indicate cells without Ad-14-3-3ל-transfected MGC-803 for which YAP expression is negative. (B) Cytoplasmic and nuclear fractions were prepared from MGC-803 cells transfected with blank vector or 14-3-3 $\zeta$-overexpressing adenovirus, and YAP protein levels were determined through western blotting. (C) and (D) Quantitative analyses of CTGF and Cy61 mRNA in MGC803 cells transfected with vector or $14-3$-3 $\zeta$-overexpressing adenovirus $\left(n=3 ;{ }^{*} p<0.05 ;{ }^{*} p<0.01\right)$. (E) and (F) Quantitative analyses

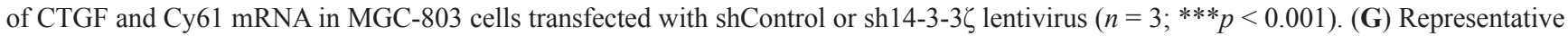
images of colony formation in MGC-803 cells transfected with a blank vector or YAP-overexpressing adenovirus and shControl or sh143-3 $\zeta$ lentivirus. The transfected cells were cultured for 5 days. (H) and (I) Quantitative analyses of CTGF and Cy61 mRNA in MGC-803 cells transfected with blank vector or YAP-overexpressing adenovirus and shControl or sh14-3-3 $\zeta$ lentivirus $\left(n=3 ;{ }^{*} p<0.05 ; * * p<0.01\right.$;

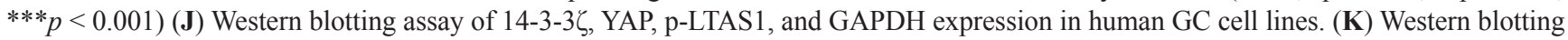

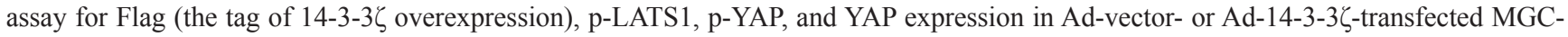

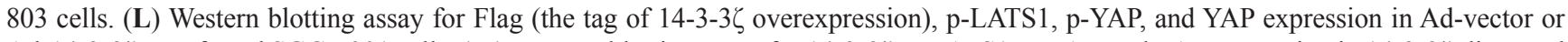

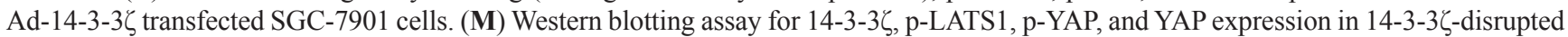

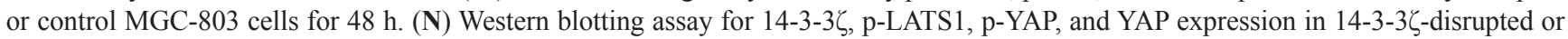
control SGC-7901 cells for 48 h. (O) 293T cells were transfected with the indicated adenoviruses and plasmids, and the luciferase activities were measured and normalized to that of Renilla. (shYAP-3'UTR is shRNA that is targeted to endogenous YAP; $n=3 ; * * * p<0.001$ ).

eight miRNAs were expressed in 293T cells; however, the overexpression and knockdown of YAP did not directly induce their expression in 293T cells (Supplementary Figure $6 \mathrm{~B}$ and $6 \mathrm{C})$. The inhibition of $14-3-3 \zeta$ by YAP was independent of its phosphorylation (Supplementary Figure 6D). This result suggested that YAP reduced 14-3-3 $\zeta$ expression through a separate posttranslational regulation.

Proteins from the 14-3-3 family are a target of ATL31 ubiquitin ligase [33]. They can be suppressed by P53 through proteasome-mediated protein degradation [34]. Studies have shown that 14-3-3 proteins may be degraded through ubiquitination [33, 34]. Our results also indicated that YAP transfection increases 14-3-3 $\zeta$ ubiquitination in MGC-803 and BGC-823 cells (Figure 6C and 6D). We confirmed this phenomenon by using the proteasome inhibitor MG132, which reversed the effect on the 14-3-3 $\zeta$ induced by YAP overexpression or knockdown (Figure 6E). Furthermore, 14-3-3 $\zeta$ was identified as an interacting protein for E3 ubiquitin ligase MDM2 [35]. The knockdown of MDM2 abolished the effect of YAP on 14-3-3 $\zeta$ (Figure 6F). A previous study reported that YAP recruits an E3 ubiquitination enzyme $(\beta-\operatorname{TrCP})$ to induce the degradation of $\beta$-catenin [36]. Furthermore, coimmunoprecipitation results revealed YAP, 14-3-3 $\zeta$, and MDM2 colocalization in 293 T and MGC803 cells (Figures 6G and Supplementary Figure 6E). Therefore, YAP may recruit MDM2 to $14-3-3 \zeta$ and promote 14-3-3 $\zeta$ ubiquitination. The binding between 14-3-3 $\zeta$ and MDM2 decreased when YAP expression was altered (Figure 6H).

\section{Verification of a YAP-14-3-3 $\zeta$ negative feedback loop through murine models}

To demonstrate the regulatory relationship between YAP and 14-3-3 $\zeta$ in murine models, we conducted in vivo tumorigenicity experiments through subcutaneous injections of the vectors, namely $14-3-3 \zeta$ and YAP-overexpressing MGC-803 cells. As indicated in Figures 2 and 3, the overexpression of YAP in vivo promoted tumorigenesis whereas $14-3-3 \zeta$ overexpression in vivo inhibited tumorigenesis (Supplementary Figure 7, Figure 7A, and 7B). YAP promoted the expression of PCNA and Cyclin-D3, whereas 14-3-3 $\zeta$ inhibited their expression (Figure 7C) Western blot and immunofluorescence assays revealed that $14-3-3 \zeta$ overexpression increased the phosphorylation of YAP at the Ser127 site in subcutaneous tumor tissue (Figure 7D and 7F). Moreover, the overexpression of YAP in subcutaneous tumor tissue reduced the expression of $14-3-3 \zeta$ (Figure $7 \mathrm{E}$ and $7 \mathrm{G}$ ). These results confirmed the existence of a YAP-14-3-3 $\zeta$ negative feedback loop in a murine model.

\section{DISCUSSION}

The Hippo pathway plays a crucial role in organ size control and tissue homeostasis [37]. Studies of mouse models and clinical samples have confirmed the significance of this pathway in the development of human cancers $[11,38,39]$. Further investigation of the functions of this pathway and the regulatory mechanisms underlying it are required to facilitate the understanding of organ size control and identify new targets for cancer treatment [40]. YAP is considered to function as an oncoprotein in numerous tumor types [13-16]. The results of the present and a previous study have revealed that YAP is upregulated in gastric adenocarcinomas and promotes cell proliferation [17]. Zhang et al. first reported that VGLL4 functions as a novel inhibitor of the YAP-TEAD transcriptional complex in lung cancer [41]. They reported that GC tumor growth can be suppressed in vitro and in vivo by the peptide mimicking function of VGLL4 [42]. In addition, RUNX3 inhibits the TEAD-YAP oncogenic complex to inhibit GC growth [43]. These studies strongly indicate that the identification of a novel inhibitory molecule may provide a breakthrough in GC treatment. In this study, we first discovered the contrasting pattern of YAP and 14-3-3 $\zeta$ expression and revealed a negative correlation between them in GC tissues. Therefore, we suspected that 14-3-3 $\zeta$ may be another inhibitory molecule of YAP in GC. Further research revealed that $14-3-3 \zeta$ inhibited 
the activation of YAP by inducing its phosphorylation in $\mathrm{GC}$ cells.

Proteins in the 14-3-3 family can bind to hundreds of partners [22]. Previous studies have reported that the role of 14-3-3 proteins in the Hippo pathway was only to bind to $127-Y A P$ and induce the cytoplasmic retention of YAP [10, 12, 26, 27]. However, our study revealed that, in addition to inducing the YAP location, the overexpression of 14-3-3 $\zeta$ promoted YAP phosphorylation. Furthermore, 14-3-3 proteins regulated target proteins in several ways, such as by changing the protein conformation, affecting protein activity or stability, altering protein subcellular localization, and facilitating protein complex formation $[20,21]$. Our previous study demonstrated that $14-3-3 \zeta$ induced YAP phosphorylation by mediating the binding of YAP and p-LATS in the Hippo pathway. In brief, the binding of p-LATS and YAP is dependent on 14-3-3 $\zeta$ and is required for YAP phosphorylation in 293T cells [29]. This finding strongly suggests that $14-3-3 \zeta$ is not just a companion molecule but also a regulator of the Hippo pathway. Our studies have clarified the novel role of 14-3$3 \zeta$ in the Hippo pathway.

The exact role of 14-3-3 proteins in cancer progression is unclear. For example, 14-3-3 $\sigma$ was initially considered a tumor suppressor in breast and prostate cancers [44-46]. However, 14-3-3 $\sigma$ is also associated with relatively unfavorable prognoses in hepatocellular carcinoma, indicating that $14-3-3 \sigma$ is an enhancer of liver cancer [47]. Thus, 14-3-3 $\sigma$ is a "double-edged sword" in human cancers [48]. In addition, $14-3-3 \zeta$ is considered to be a central cellular hub protein that regulates the multiple signaling pathways involved in cancer progression [49]. In prostate cancer, $14-3-3 \zeta$ is overexpressed and facilitates

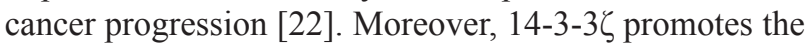
phosphorylation of AKT by binding to the $\mathrm{p} 85$ regulatory subunit, which primes human breast cancer cells for invasion in response to ionizing radiation [23, 24]. A recent study revealed that $14-3-3 \zeta$ alters the function of TGF- $\beta$ from that of a tumor suppressor to a metastasis promoter by changing the Smad partner from p53 to Gli2 [25]. The aforementioned studies clearly demonstrate that $14-3-3 \zeta$ is a cancer promoter. However, approximately $35.7 \%$ of GC tissue samples expressed lower 14-3-3 $\zeta$ than did their paired adjacent tissues, and 14-3-3 $\zeta$ overexpression significantly inhibited cell proliferation in multiple GC cell lines; the aforementioned characterization of $14-3-3 \zeta$

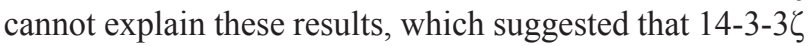
may be also a double-edged sword for GC.

Because of the vital role of 14-3-3 proteins in the Hippo signaling pathway, understanding the action of 143-3 $\zeta$ on YAP is crucial. However, few studies have focused on clarifying this action. Our review of the relevant
A
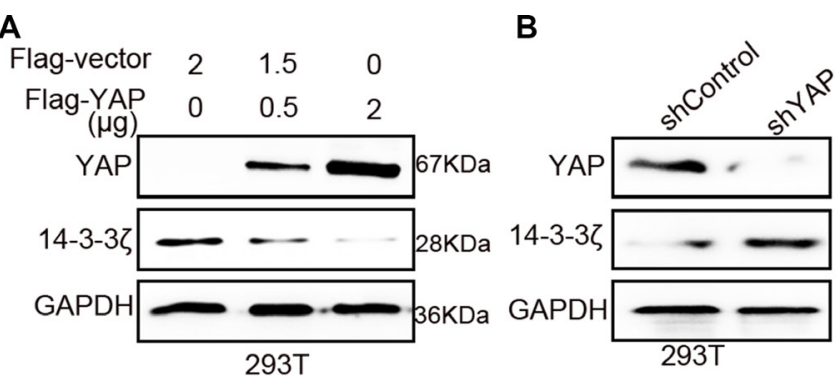

C
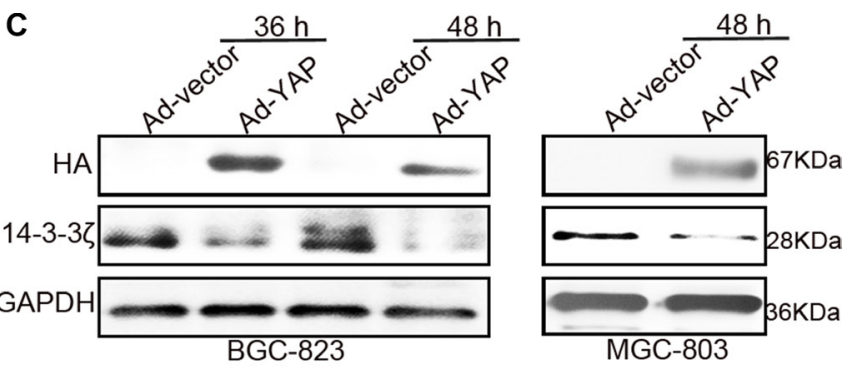

D
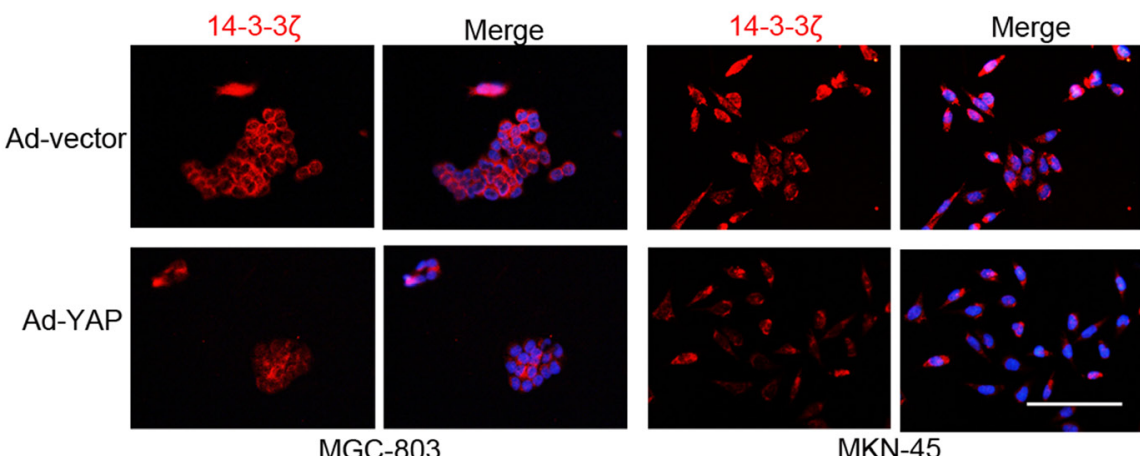

MGC-803
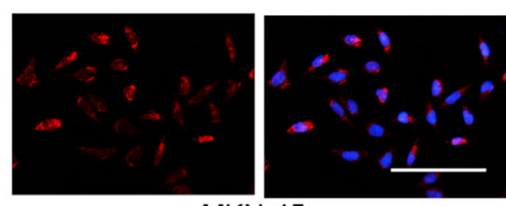

MKN-45
E

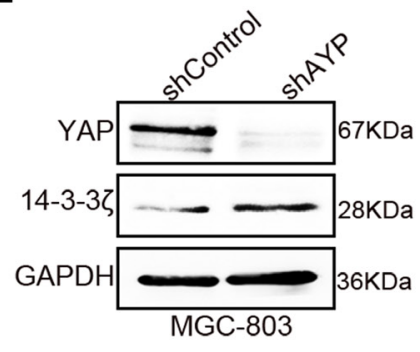

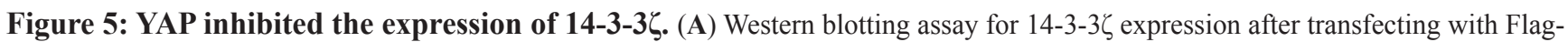
vector or -YAP plasmid in 293T cells for $60 \mathrm{~h}$. (B) The expression of 14-3-3 $\zeta$ was detected in YAP-disrupted or control $293 \mathrm{~T}$ cells through western blotting after $48 \mathrm{~h}$. (C) Western blotting assay for 14-3-3 $\zeta$ expression in BGC-823 and MGC-803 cells after transfecting with vector or YAP-overexpressing adenovirus at the indicated time point. (D) Representative images of 14-3-3 $\zeta$ immunofluorescence staining

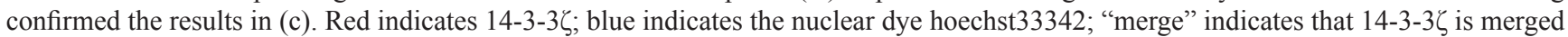

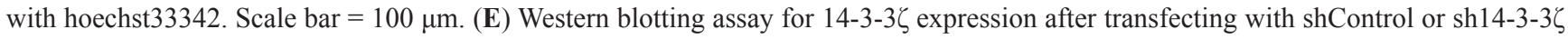
lentivirus for $48 \mathrm{~h}$ in MGC-803 cells. 
A

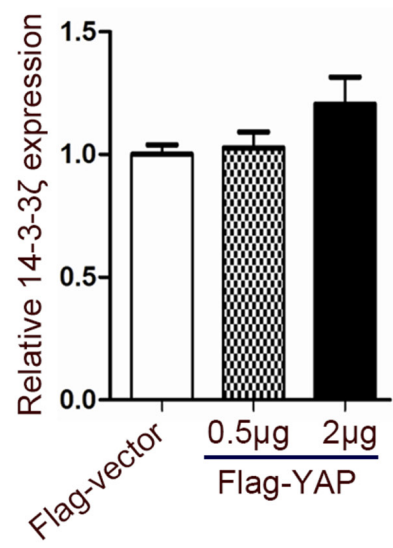

B

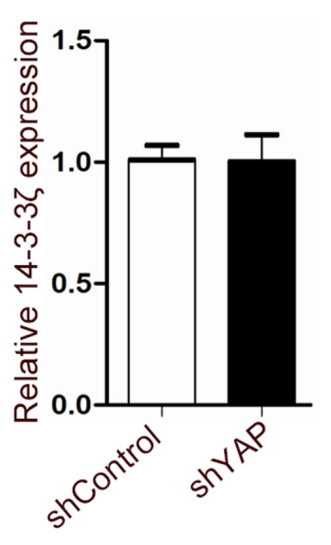

C

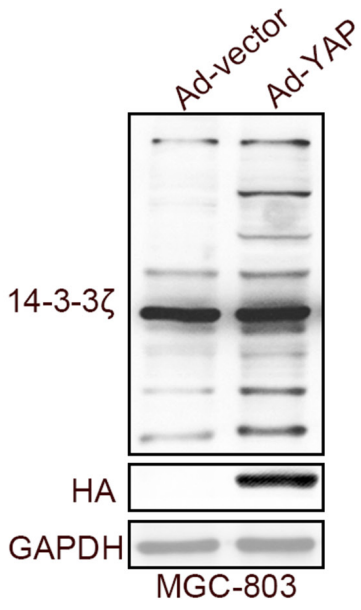

D

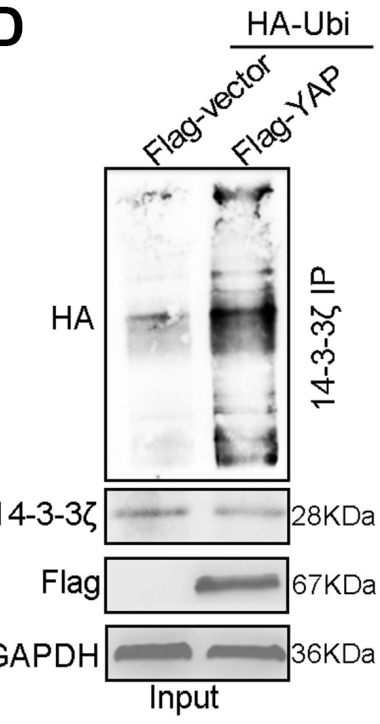

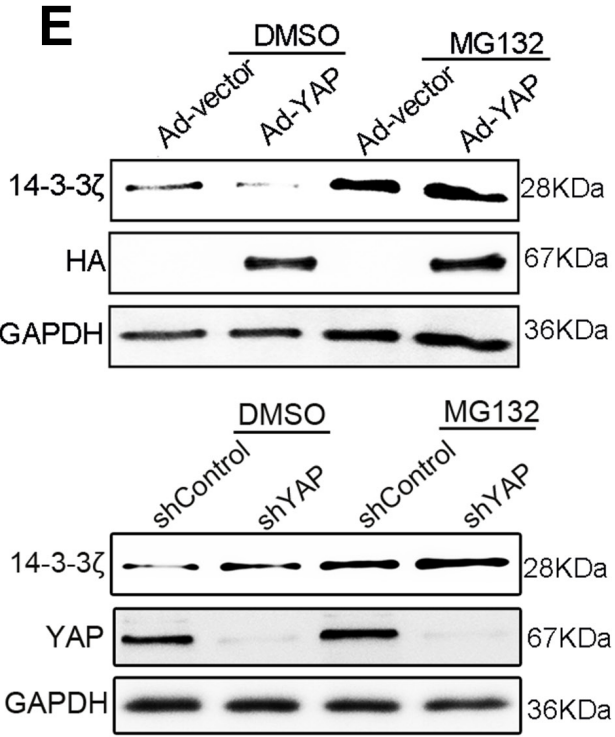

$\mathbf{F}$

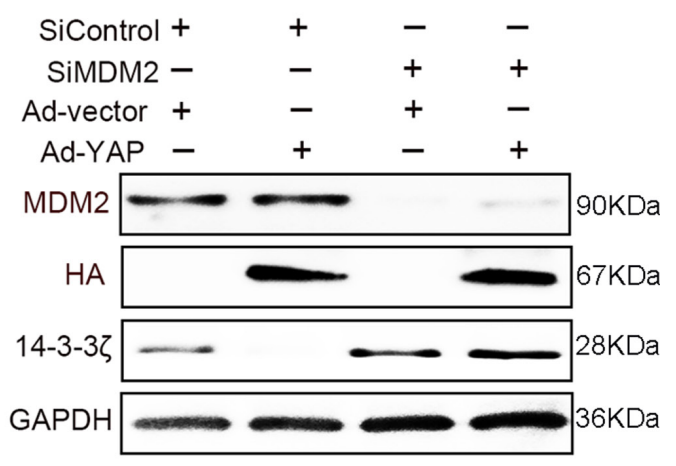

G

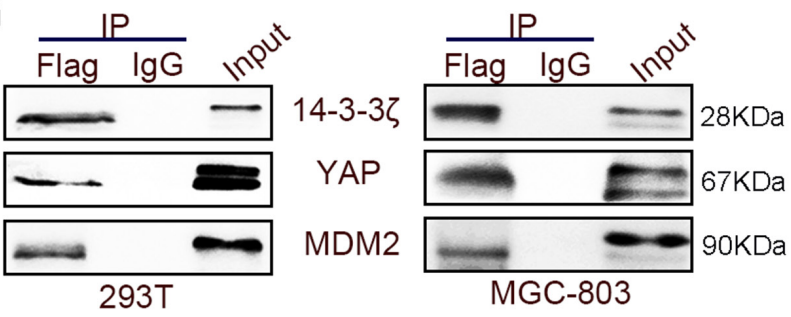

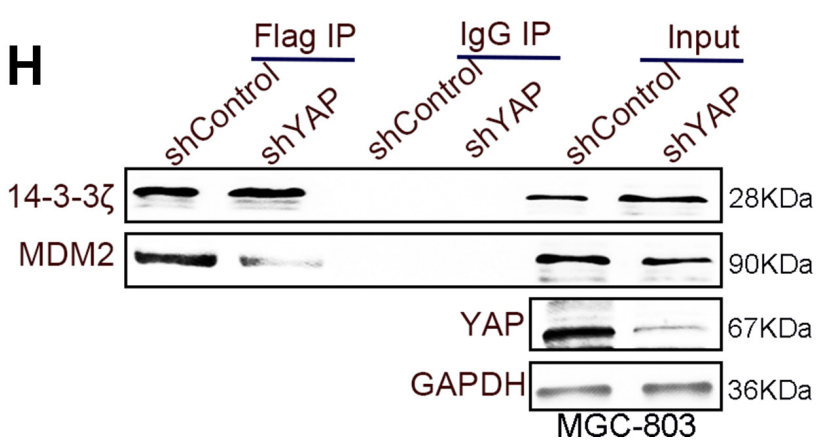

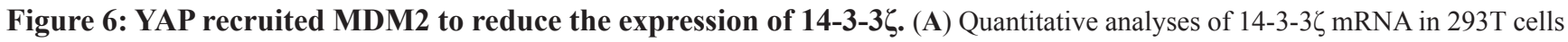
transfected with Flag-vector or -YAP plasmid for $60 \mathrm{~h}$. (B) The expression of 14-3-3 $\zeta$ mRNA was detected in YAP-disrupted or control $293 \mathrm{~T}$ cells through qRT-PCR after $48 \mathrm{~h}$. (C) MGC-803 cells were transfected with vector and YAP-overexpressing adenovirus for $60 \mathrm{~h}$. The

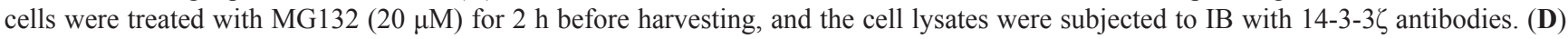
$293 \mathrm{~T}$ cells were transfected with the indicated plasmids for $48 \mathrm{~h}$. The cells were treated with MG132 $(20 \mu \mathrm{M})$ for $2 \mathrm{~h}$ before harvesting,

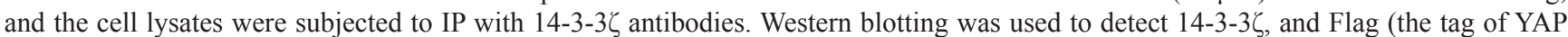
overexpression). (E) Western blotting assay for 14-3-3 $\zeta$ expression in YAP-disturbed or YAP-overexpressing adenovirus-transfected MGC803 cells after treating with or without MG132 $(20 \mu \mathrm{M})$. (F) The expression of HA (the tag of YAP overexpression), MDM2, and 14-3-3 $\zeta$ was determined in YAP-overexpressing or nonoverexpressing MGC-803 cells with or without the disruption of MDM2 expression. (G) 14-

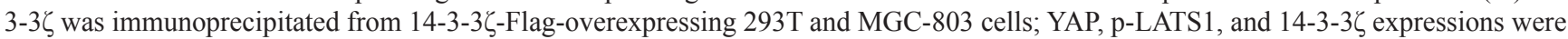
determined through western blotting. (H) YAP-disrupted or control MGC-803 cells were transfected with 14-3-3 $\zeta$-Flag-overexpressing adenovirus and subjected to IP using Flag antibodies or control IgG, followed by IB with YAP, MDM2, and 14-3-3 $\zeta$ antibodies. 
A

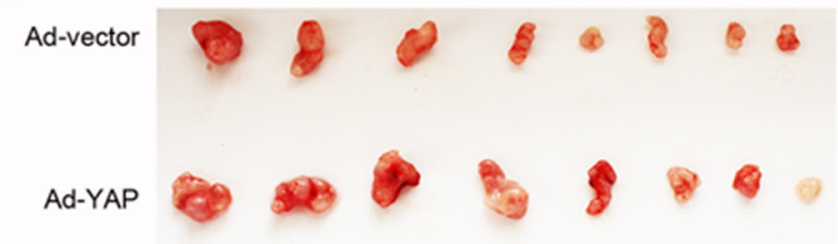

Ad-14-3-3

C

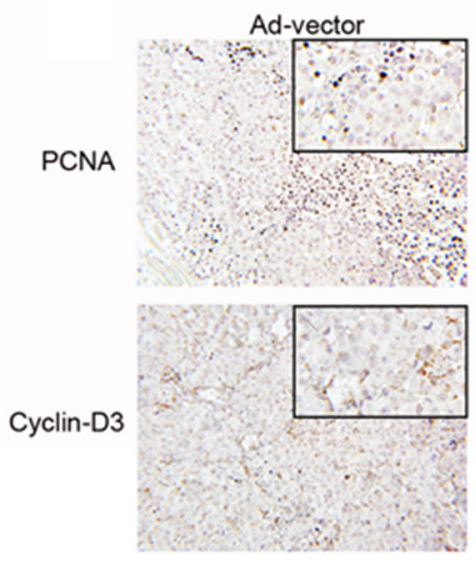

D

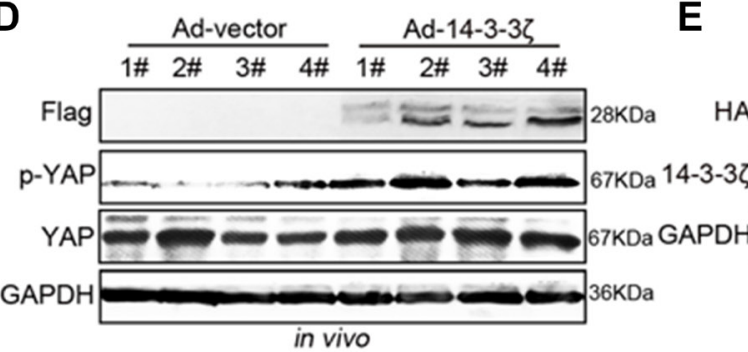

E
B

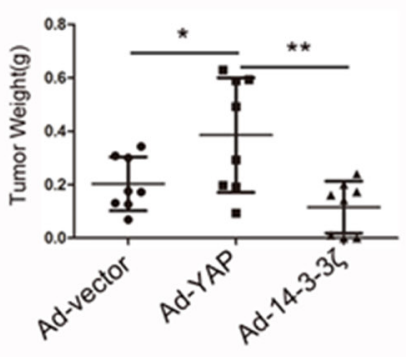

Ad-YAP

Ad-14-3-32
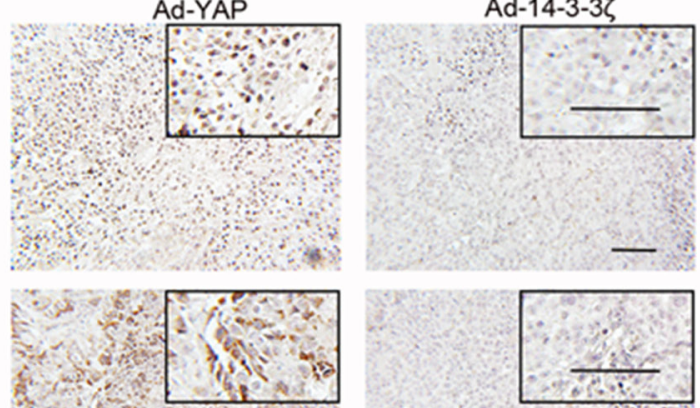

$\mathbf{F}$
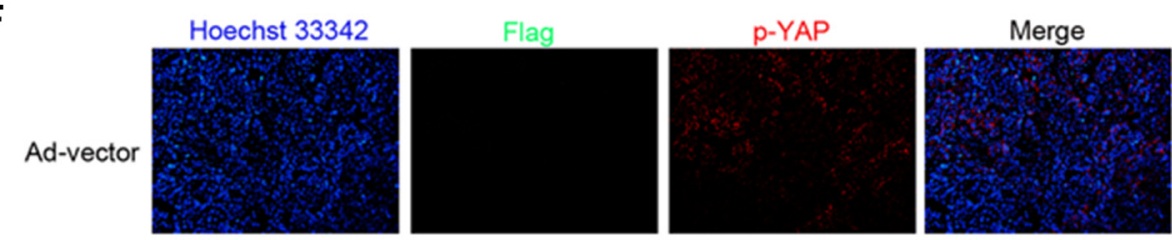

Ad-14-3-37
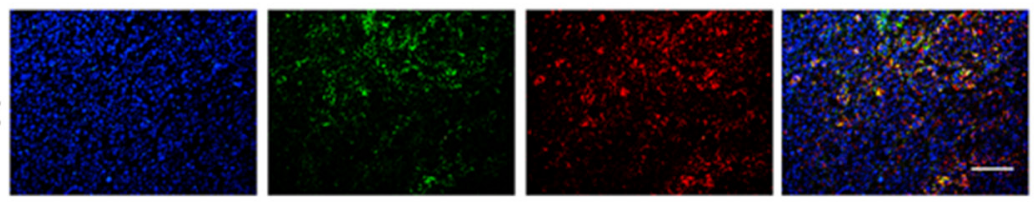

G
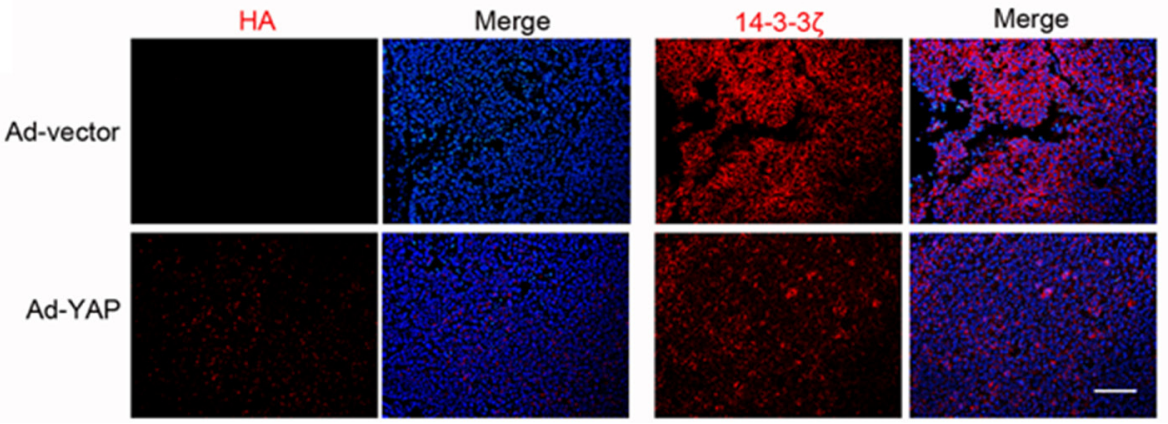
Figure 7: Verification of the YAP/14-3-3 ל regulatory relationship in a murine model. (A) Representative images of subcutaneous tumors. (B) Tumor weight was evaluated in mice transfected with blank vector, YAP-overexpressing, and 14-3-3 -overexpressing MGC803 cells. (C) Representative images of PCNA and Cyclin-D3 histochemical staining in the subcutaneous tumors tissues displayed in Figure 7A. Scale bar $=100 \mu \mathrm{m}$. (D) Western blotting assay for Flag (the tag for 14-3-3 $\zeta$ overexpression expressed by the adenovirus vector), p-YAP, YAP, and GAPDH expressions in subcutaneous tumor tissue that was produced through injection with Ad-vector and Ad-14-3-3 $\zeta$ transfected MGC-803 cells. (E) Western blotting assay for HA (the tag for YAP overexpression expressed by the adenovirus vector), p-YAP, YAP, and GAPDH expression in tumor tissue that was produced through subcutaneous injection with Ad-vector and Ad-YAP transfected

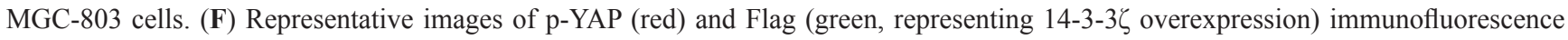

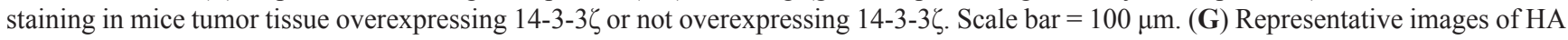

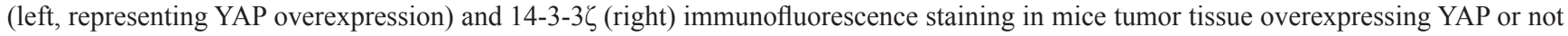
overexpressing YAP. Scale bar $=100 \mu \mathrm{m}$.

literature indicated that this study is the first to report that YAP reduced the expression of 14-3-3 $\zeta$ but not its mRNA level. On the basis that YAP can directly promote miRNA130a transcription and inhibit VGLL4 expression [32], we hypothesized that YAP inhibited 14-3-3 $\zeta$ gene translation by first expressing some miRNAs. However, YAP did not induce the expression of miRNAs that can repress the

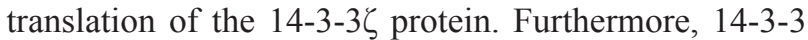
proteins can be degraded through ubiquitination [33, 34], and 14-3-3 $\zeta$ was an interacting protein for the E3 ubiquitin ligase MDM2 [35]. MDM2 inhibits the P53 pathway by inducing P53 ubiquitination [50]. However, whether 14-3$3 \zeta$ can be ubiquitinated by MDM2 remains unknown. Our results reveal that the knockdown of MDM2 abolished the reduction of 14-3-3 $\zeta$ induced by YAP in MGC-803 cells. We observed the novel finding that MDM2 is involved in the Hippo pathway through the regulation of the YAP-14$3-3 \zeta$ axis.

In summary, we first revealed that $14-3-3 \zeta$ and YAP formed a special negative feedback loop in GC and affected cell proliferation. The $14-3-3 \zeta$ protein induced the cytoplasmic retention of YAP and inhibited its transcriptional activity by mediating the binding of YAP and p-LATS. By contrast, YAP recruited MDM2 to 14-3$3 \zeta$ and reduced the stability of $14-3-3 \zeta$.

\section{MATERIALS AND METHODS}

\section{Human gastric cancer samples}

The primary GC tissues and their matching adjacent noncancerous tissues (located more than 5-10 cm away from the primary site) were collected from patients with GC undergoing surgery at the Affiliated Hospital of Jiangsu University in Zhenjiang, Jiangsu, China.

Tissue microarrays of 178 primary gastric tumor cases were used for detecting YAP and 14-3-3 $\zeta$ expression; the samples were preserved in the Gastric Cancer Tissue Bank at the Department of Oncology, Changzheng Hospital (Shanghai, China). All the cases underwent curative resection. In addition, all tissue specimens for this study were obtained with patients' informed consent, and the study protocols were approved by the institutional review boards of Chang Zheng Hospital and Jiangsu University.

\section{Cell lines and cell culture}

The human GC cell lines SGC-7901, AGS, HGC27, BGC-823, MKN-45, and MGC80-3 were purchased from the Institute of Biochemistry and Cell Biology at the Chinese Academy of Sciences (Shanghai, China). SGC7901, AGS, and HGC-27 cells were cultured in RPMI1640 medium (Gibco, Grand Island, NY, USA). BGC-823, MKN-45, and MGC80-3 cells were propagated in a highglucose Dulbecco's modified Eagle's medium (Gibco, Grand Island, NY, USA). All media were supplemented with $10 \%$ fetal bovine serum. The cells were cultured at $37^{\circ} \mathrm{C}$ in humidified air with $5 \% \mathrm{CO}_{2}$.

\section{Immunohistochemistry}

Immunohistochemistry was used to detect YAP (1:50; Bioworld, Louis Park, MN, USA) and 14-3-3ל (1:100; Bioworld, Louis Park, MN, USA). Images were sequentially acquired through microscopy (Nikon, Tokyo, Japan).

\section{Colony formation assay}

The cells were harvested and seeded into a 6-well plate $\left(1000\right.$ cells/well) and incubated at $37^{\circ} \mathrm{C}$ in a $5 \% \mathrm{CO}_{2}$ humidified incubator for the indicated time. At the end of the incubation period, the cultures were fixed with $4 \%$ paraformaldehyde and stained with crystal violet.

\section{Western blotting}

Cell and tissue lysates were extracted in a lysis buffer containing $50 \mathrm{mM}$ sodium chloride $(\mathrm{NaCl}), 1$ $\mathrm{mM}$ ethylene glycol tetraacetic acid, $0.1 \%$ sodium dodecyl sulfate (SDS), $1 \mathrm{mM}$ sodium fluoride, $1 \mathrm{mM}$ sodium orthovanadate, $1 \mathrm{mg} / \mathrm{mL}$ aprotinin, and $1 \mathrm{mg} / \mathrm{mL}$ leupeptin in $10 \mathrm{mM}$ Tris buffer $(\mathrm{pH} \mathrm{7.4)}$ ) and proteinase inhibitor ( $1 \mathrm{mM} \mathrm{n}$-phenylmethanesulfonyl fluoride). Equal amounts of the total protein were separated on a $12 \%$ SDS-polyacrylamide gel and transferred to nitrocellulose membranes (Millipore). The membranes were incubated 
overnight with monoclonal antibodies against GAPDH, PCNA, cyclin-D1, cyclin-D3, YAP, p-YAP, 14-3-3 , LATS1, MDM2, histone, Flag, and haemagglutinin (HA) (Supplementary Table 1). The membrane was washed three times with tris-buffered saline and Tween and incubated with secondary antibodies (Bioworld, Louis Park, MN, USA) at $37^{\circ} \mathrm{C}$ for $1 \mathrm{~h}$. The signals were visualized using a Luminata crescendo western horseradish peroxidase substrate (Millipore, Billerica, MA, USA).

\section{RNA extraction, RT-PCR, and real-time RT- PCR (mRNA)}

Total RNA was isolated from skin cells and tissues by using Trizol reagents (Invitrogen, Carlsbad, CA, USA). Two-microgram aliquots of RNA were synthesized according to the manufacturer's protocol (Vazyme, Nanjing, China). Real-time polymerase chain reaction (PCR) reactions were conducted using the QuantiTect SYBR Green PCR kit (Toyobo). The primer sequences are listed in Supplementary Table 2.

\section{RT-PCR and real-time RT-PCR for miRNAs}

The poly(A) tailing kit (New England Biolabs, MA, USA) was used for detecting miRNA as follows: $1 \mu \mathrm{g}$ of total RNA was mixed with $2 \mu \mathrm{L}$ poly(A) buffer (10 nM), $2 \mu \mathrm{L}$ ATP $(10 \mathrm{nM})$, and $0.5 \mu \mathrm{L}$ Escherichia coli poly(A) polymerase I. The total volume was adjusted to $20 \mu \mathrm{L}$ with RNase-free $\mathrm{dd}_{2} \mathrm{O}$. Furthermore, single-stranded cDNA was obtained from RNA by using reverse transcriptase (Takara, China). A total of $0.5 \mu \mathrm{g}$ of total poly(A)-tailing RNA was mixed with $2 \mu \mathrm{L}$ of M-MLV buffer $(5 \times)$, $0.5 \mu \mathrm{L}$ of a dNTP mixture (10 mM), $0.25 \mu \mathrm{L}$ of an RNase inhibitor $(40 \mathrm{U} / \mu \mathrm{L}), 0.25 \mu \mathrm{L}$ of RTase M-MLV (RNase $\mathrm{H} ; 200 \mathrm{U} / \mu \mathrm{L})$, and $1 \mu \mathrm{L}$ of adaptor(dT) $15(50 \mu \mathrm{L} \mathrm{M})$. Furthermore, the total volume was adjusted to $20 \mu \mathrm{L}$ with RNase-free $\mathrm{ddH}_{2} \mathrm{O}$. Reverse transcription was performed at $42^{\circ} \mathrm{C}$ for $60 \mathrm{~min}$, followed by an inactivation reaction at $70^{\circ} \mathrm{C}$ for $15 \mathrm{~min}$. The PCR mixture contained $10 \mu \mathrm{L}$ of the qPCR master mix ( $2 \times$; Bio-Rad, CA, USA) and $1 \mu \mathrm{L}$ of cDNA; the total volume was increased to $20 \mu \mathrm{L}$ with $\mathrm{ddH}_{2} \mathrm{O}$. The primer powder was fixed to the bottom of a 96-well plate and $20 \mu \mathrm{L}$ of the PCR mixture was added to each well. Reverse transcription (RT)-PCR was performed using the CFX96 real-time instrument (BioRad). Furthermore, real-time RT-PCR was performed using the SYBR Green q-PCR Super mix (Bio-Rad) with specific primers (Supplementary Table 2). The thermal cycle parameters were as follows: $95^{\circ} \mathrm{C}$ for $5 \mathrm{~min}$, 40 cycles at $95^{\circ} \mathrm{C}$ for $15 \mathrm{~s}, 60^{\circ} \mathrm{C}$ for $15 \mathrm{~s}, 72^{\circ} \mathrm{C}$ for $20 \mathrm{~s}$, and a $65-95^{\circ} \mathrm{C}$ drawing dissociation curve. The expression of each gene was defined from the threshold cycle $(\mathrm{Ct})$, and the melting temperatures were recorded. The relative changes in miRNA expression were analyzed through the $\Delta \Delta \mathrm{Ct}$ method.

\section{Cytoplasm and nuclear fractionation}

Cytoplasm and nuclear fractionation were performed according to the manufacturer's instructions (Vazyme, Nanjing, China). In brief, the cells were harvested and washed once with cold phosphate-buffered saline (PBS). The cells were then suspended in isolation buffer A mixed with protease inhibitors and rotated at $4^{\circ} \mathrm{C}$ for $1 \mathrm{~min}$. After $12,000 \times \mathrm{g}$ centrifugation at $4^{\circ} \mathrm{C}$ for $5 \mathrm{~min}$, the supernatant, containing the cytoplasm fraction, was collected. The remaining cell debris were suspended in isolation buffer $\mathrm{B}$ mixed with protease inhibitors and centrifuged three times every $10 \mathrm{~min}$ at $4^{\circ} \mathrm{C}$ for $1 \mathrm{~min}$. The samples for cytoplasm and nuclear fractionation were stored at $-80^{\circ} \mathrm{C}$ in preparation for western blot detection.

\section{Luciferase assay}

For the YAP reporter assay, HEK293T cells were seeded in 24-well plates. A combination of $5 \times$ UASluciferase reporter, b-actin-Renilla, 3 × Flag-YAP, GAL4TEAD4, and other indicated plasmids was cotransfected as indicated in Figure 4O. After $48 \mathrm{~h}$ following transfection, cells were lysed and luciferase activity was assayed using an enhanced luciferase assay kit obtained from Promega following the manufacturer's instructions. All luciferase activities were normalized to Renilla activity.

\section{Cell counting assay}

In total, $5 \times 10^{3} \mathrm{MGC}-803$, HGC-27, and MKN-45 cells were plated in each well of the 24 -well plates for cell counting assay. The number of cells in each well was counted in triplicate at different time points.

\section{Lentiviral knockdown of target genes in cells}

The lentiviral expression vector containing the shRNA sequence (Sigma) was selected for target-specific gene silencing; the target genes are listed in Supplementary Table 3. Lenti-GFP-shRNA was used as the negative control vector. The shRNA sequences of control and target-specific genes are listed in Supplementary Table 3. The shRNA lentiviral vectors were generated by ligating the vector Tet-pLKO-puro; these lentiviral vectors were produced using a lentivirus packaging mix (ViraPower, Invitrogen). In addition, stable cell lines were obtained after selection with $1 \mu \mathrm{g} / \mathrm{mL}$ of puromycin (Invitrogen) for 15 days. The expression of shRNA was induced by adding $80 \mu \mathrm{g} / \mathrm{mL}$ doxycycline for 2 days. The efficiency of wnt 4 
knockdown was evaluated through real-time quantitative RT-PCR and western blotting.

\section{Immunoprecipitation}

The cells were lysed in a co-immunoprecipitation (IP) buffer (10 mM HEPES [pH 8.0], $300 \mathrm{mM} \mathrm{NaCl}, 0.1$ mM EDTA, 20\% glycerol, $0.2 \%$ NP-40, and protease and phosphatase inhibitors). The lysates were centrifuged and cleared through incubation with $25 \mu \mathrm{L}$ of a protein $\mathrm{A} / \mathrm{G}$ gel for $1.5 \mathrm{~h}$ at $4^{\circ} \mathrm{C}$. The precleared supernatant was then subjected to IP using the indicated antibodies at $4{ }^{\circ} \mathrm{C}$ overnight. The protein complexes were then collected by incubating with $30 \mu \mathrm{L}$ of protein $\mathrm{A} / \mathrm{G}$ gel for $2 \mathrm{~h}$ at $4^{\circ} \mathrm{C}$. The collected protein complexes were washed six times with a co-IP buffer and analyzed through western blotting.

\section{siRNA transfection}

Chemically synthesized MDM2 siRNAs and the matching scramble control siRNAs were purchased from GenePharma Co., Ltd (Shanghai, China; Supplementary Table 3). The siRNAs were transiently transfected into SGC-7901 and MGC803 cells by using Lipofectamine 2000 reagent (Invitrogen, Carlsbad, CA, USA) according to the manufacturer's instructions. The cells were plated in 6-well plates at a density of $1 \times 10^{5}$ cells/well. The transfection reagent and scrambled siRNA-transfected cells were used as controls.

\section{In vivo tumorigenicity}

Twelve male BALB/c nu/nu mice (Laboratory Animal Center of Shanghai, Academy of Science, Shanghai, China) aged 4-6 weeks were randomly divided into three groups (four mice per group). All the groups received subcutaneous injections of the vector, namely 14-3-3 $\zeta$ - and YAP-overexpressing MGC-803 cells $\left(2 \times 10^{6}\right.$ cells in $200 \mu \mathrm{L}$ PBS $)$ on both sides of their upper limbs. Tumor growth was evaluated through weight measurement.

\section{Cell scratch assay}

MGC- 803 cells were seeded at a density of $2 \times 10^{5}$ cells/well in 6-well plates and incubated at $37^{\circ} \mathrm{C}$ in $5 \% \mathrm{CO}_{2}$ for $24 \mathrm{~h}$ to create confluent monolayers. The monolayers were scratched with a sterile pipette tip. To measure cell mobility, we stained the cells with crystal violet and obtained images in five random fields at $24 \mathrm{~h}$ after scratching.

\section{Statistical analysis}

All data are presented as means \pm standard deviation (SD). The correlation of the expression levels of YAP and
14-3-3 $\zeta$ in gastric tissue microarrays was analyzed using the chi-square test (SPSS Statistics version 20 software). Overall survival curves were plotted according to the Kaplan-Meier method, with the log-rank test was applied for comparison. The statistically significant differences between groups were assessed using analysis of variance and $t$-tests with the Prism software package (GraphPad, San Diego, USA). A $p$ value of less than 0.05 was considered statistically significant.

\section{ACKNOWLEDGMENTS}

This work was supported by the National Natural Science Foundation of China (Grant no. 31340040, $81272481,81270214,81572075,81602883)$, China Postdoctoral Science Foundation Funded Project (no. 2016M591792, 2016M600383), Jiangsu Province for Outstanding Sci-tech Innovation Team in Colleges and Universities (Grant SJK2013-10), Jiangsu Province's Outstanding Medical Academic Leader and Sci-tech Innovation Team Program (Grant no. LJ201117), and the Priority Academic Program Development of Jiangsu Higher Education Institutions.

\section{CONFLICTS OF INTEREST}

The authors declare no competing financial interests.

\section{REFERENCES}

1. Jemal A, Bray F, Center MM, Ferlay J, Ward E, Forman D. Global cancer statistics. CA Cancer J Clin. 2011; 61:69-90.

2. Pornsuksiri K, Chewatanakornkul S, Kanngurn S, Maneechay W, Chaiyapan W, Sangkhathat S. Clinical outcomes of gastrointestinal stromal tumor in southern Thailand. World J Gastrointest Oncol. 2012; 4:216-22.

3. Bertuccio P, Chatenoud L, Levi F, Praud D, Ferlay J, Negri E, Malvezzi M, La Vecchia C. Recent patterns in gastric cancer: a global overview. Int J Cancer. 2009; 125:666-73.

4. $\mathrm{Yu} \mathrm{B}, \mathrm{Xie}$ J. Identifying therapeutic targets in gastric cancer: the current status and future direction. Acta Biochim Biophys Sin (Shanghai). 2016; 48:90-96.

5. Wang $\mathrm{M}, \mathrm{Gu} \mathrm{H}$, Qian $\mathrm{H}$, Zhu W, Zhao C, Zhang X, Tao Y, Zhang L, Xu W. miR-17-5p/20a are important markers for gastric cancer and murine double minute 2 participates in their functional regulation. Eur J Cancer. 2013; 49:2010-21.

6. Edgar BA. From cell structure to transcription: hippo forges a new path. Cell. 2006; 124:267-73.

7. Harvey K, Tapon N. The Salvador-Warts-Hippo pathway an emerging tumour-suppressor network. Nat Rev Cancer. 2007; 7:182-91.

8. Pan D. The hippo signaling pathway in development and cancer. Dev Cell. 2010; 19:491-505. 
9. Zhao B, Li L, Guan KL. Hippo signaling at a glance. J Cell Sci. 2010; 123:4001-06.

10. Zhao B, Li L, Lei Q, Guan KL. The Hippo-YAP pathway in organ size control and tumorigenesis: an updated version. Genes Dev. 2010; 24:862-74.

11. Dong J, Feldmann G, Huang J, Wu S, Zhang N, Comerford SA, Gayyed MF, Anders RA, Maitra A, Pan D. Elucidation of a universal size-control mechanism in Drosophila and mammals. Cell. 2007; 130:1120-33.

12. Zhao B, Wei X, Li W, Udan RS, Yang Q, Kim J, Xie J, Ikenoue T, Yu J, Li L, Zheng P, Ye K, Chinnaiyan A, et al. Inactivation of YAP oncoprotein by the Hippo pathway is involved in cell contact inhibition and tissue growth control. Genes Dev. 2007; 21:2747-61.

13. Moroishi T, Hansen CG, Guan KL. The emerging roles of YAP and TAZ in cancer. Nat Rev Cancer. 2015; 15:73-79.

14. Harvey KF, Zhang X, Thomas DM. The Hippo pathway and human cancer. Nat Rev Cancer. 2013; 13:246-57.

15. Hua G, Lv X, He C, Remmenga SW, Rodabough KJ, Dong J, Yang L, Lele SM, Yang P, Zhou J, Karst A, Drapkin RI, Davis JS, et al. YAP induces high-grade serous carcinoma in fallopian tube secretory epithelial cells. Oncogene. 2016; 35:2247-65. https://doi.org/10.1038/onc.2015.288.

16. Johnson R, Halder G. The two faces of Hippo: targeting the Hippo pathway for regenerative medicine and cancer treatment. Nat Rev Drug Discov. 2014; 13:63-79.

17. Zhang J, Xu ZP, Yang YC, Zhu JS, Zhou Z, Chen WX. Expression of Yes-associated protein in gastric adenocarcinoma and inhibitory effects of its knockdown on gastric cancer cell proliferation and metastasis. Int $\mathrm{J}$ Immunopathol Pharmacol. 2012; 25:583-90.

18. Aitken A. 14-3-3 proteins on the MAP. Trends Biochem Sci. 1995; 20:95-97.

19. Aitken A. 14-3-3 proteins: a historic overview. Semin Cancer Biol. 2006; 16:162-72. https://doi.org/10.1016/j. semcancer.

20. Pozuelo Rubio M, Geraghty KM, Wong BH, Wood NT, Campbell DG, Morrice N, Mackintosh C. 14-3-3-affinity purification of over 200 human phosphoproteins reveals new links to regulation of cellular metabolism, proliferation and trafficking. Biochem J. 2004; 379:395-408.

21. Jin J, Smith FD, Stark C, Wells CD, Fawcett JP, Kulkarni S, Metalnikov P, O’Donnell P, Taylor P, Taylor L, Zougman A, Woodgett JR, Langeberg LK, et al. Proteomic, functional, and domain-based analysis of in vivo 14-3-3 binding proteins involved in cytoskeletal regulation and cellular organization. Curr Biol. 2004; 14:1436-50.

22. Murata T, Takayama K, Urano T, Fujimura T, Ashikari D, Obinata D, Horie-Inoue K, Takahashi S, Ouchi Y, Homma Y, Inoue S. 14-3-3 ל, a novel androgen-responsive gene, is upregulated in prostate cancer and promotes prostate cancer cell proliferation and survival. Clin Cancer Res. 2012; 18:5617-27.

23. Neal CL, Xu J, Li P, Mori S, Yang J, Neal NN, Zhou X, Wyszomierski SL, Yu D. Overexpression of $14-3-3 \zeta$ in cancer cells activates $\mathrm{PI} 3 \mathrm{~K}$ via binding the $\mathrm{p} 85$ regulatory subunit. Oncogene. 2012; 31:897-906.

24. Kambach DM, Sodi VL, Lelkes PI, Azizkhan-Clifford J,

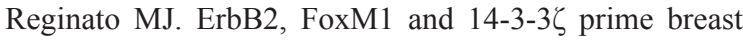
cancer cells for invasion in response to ionizing radiation. Oncogene. 2014; 33:589-98.

25. Xu J, Acharya S, Sahin O, Zhang Q, Saito Y, Yao J, Wang H, Li P, Zhang L, Lowery FJ, Kuo WL, Xiao Y, Ensor J, et al. 14-3-3 $\zeta$ turns TGF- $\beta$ 's function from tumor suppressor to metastasis promoter in breast cancer by contextual changes of Smad partners from p53 to Gli2. Cancer Cell. 2015; 27:177-92.

26. Feng Y, Irvine KD. Fat and expanded act in parallel to regulate growth through warts. Proc Natl Acad Sci USA. 2007; 104:20362-67.

27. Lei QY, Zhang H, Zhao B, Zha ZY, Bai F, Pei XH, Zhao $\mathrm{S}$, Xiong Y, Guan KL. TAZ promotes cell proliferation and epithelial-mesenchymal transition and is inhibited by the hippo pathway. Mol Cell Biol. 2008; 28:2426-36.

28. Sambandam SA, Kasetti RB, Xue L, Dean DC, Lu Q, Li Q. 14-3-3 $\sigma$ regulates keratinocyte proliferation and differentiation by modulating Yap1 cellular localization. J Invest Dermatol. 2015; 135:1621-28.

29. Zhang B, Shi Y, Gong A, Pan Z, Shi H, Yang H, Fu H, Yan Y, Zhang X, Wang M, Zhu W, Qian H, Xu W. HucMSC Exosome-Delivered 14-3-3 $\zeta$ Orchestrates Self-Control of the Wnt Response via Modulation of YAP During Cutaneous Regeneration. Stem Cells. 2016; 34:2485-500.

30. Nishimura Y, Komatsu S, Ichikawa D, Nagata H, Hirajima S, Takeshita H, Kawaguchi T, Arita T, Konishi H, Kashimoto K, Shiozaki A, Fujiwara H, Okamoto K, et al. Overexpression of YWHAZ relates to tumor cell proliferation and malignant outcome of gastric carcinoma. Br J Cancer. 2013; 108:1324-31.

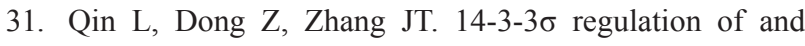
interaction with YAP1 in acquired gemcitabine resistance via promoting ribonucleotide reductase expression. Oncotarget. 2016; 7:17726-36. https://doi.org/10.18632/ oncotarget. 7394

32. Shen S, Guo X, Yan H, Lu Y, Ji X, Li L, Liang T, Zhou D, Feng XH, Zhao JC, Yu J, Gong XG, Zhang L, Zhao B. A miR-130a-YAP positive feedback loop promotes organ size and tumorigenesis. Cell Res. 2015; 25:997-1012.

33. Sato T, Maekawa S, Yasuda S, Domeki Y, Sueyoshi K, Fujiwara M, Fukao Y, Goto DB, Yamaguchi J. Identification of 14-3-3 proteins as a target of ATL31 ubiquitin ligase, a regulator of the $\mathrm{C} / \mathrm{N}$ response in Arabidopsis. Plant J. 2011; 68:137-46.

34. Chen DY, Dai DF, Hua Y, Qi WQ. p53 suppresses 14-3$3 \gamma$ by stimulating proteasome-mediated $14-3-3 \gamma$ protein degradation. Int J Oncol. 2015; 46:818-24.

35. Nicholson J, Scherl A, Way L, Blackburn EA, Walkinshaw MD, Ball KL, Hupp TR. A systems wide mass spectrometric based linear motif screen to identify dominant in-vivo 
interacting proteins for the ubiquitin ligase MDM2. Cell Signal. 2014; 26:1243-57.

36. Azzolin L, Panciera T, Soligo S, Enzo E, Bicciato S, Dupont S, Bresolin S, Frasson C, Basso G, Guzzardo V, Fassina A, Cordenonsi M, Piccolo S. YAP/TAZ incorporation in the $\beta$-catenin destruction complex orchestrates the Wnt response. Cell. 2014; 158:157-70.

37. Zhao B, Tumaneng K, Guan KL. The Hippo pathway in organ size control, tissue regeneration and stem cell self-renewal. Nat Cell Biol. 2011; 13:877-83. https://doi.org/10.1038/ncb2303.

38. Steinhardt AA, Gayyed MF, Klein AP, Dong J, Maitra A, Pan D, Montgomery EA, Anders RA. Expression of Yesassociated protein in common solid tumors. Hum Pathol. 2008; 39:1582-89.

39. Zhou D, Conrad C, Xia F, Park JS, Payer B, Yin Y, Lauwers GY, Thasler W, Lee JT, Avruch J, Bardeesy N. Mst1 and Mst2 maintain hepatocyte quiescence and suppress hepatocellular carcinoma development through inactivation of the Yap1 oncogene. Cancer Cell. 2009; 16:425-38.

40. Yu FX, Zhao B, Guan KL. Hippo Pathway in Organ Size Control, Tissue Homeostasis, and Cancer. Cell. 2015; 163:811-28.

41. Zhang W, Gao Y, Li P, Shi Z, Guo T, Li F, Han X, Feng Y, Zheng C, Wang Z, Li F, Chen H, Zhou Z, et al. VGLL4 functions as a new tumor suppressor in lung cancer by negatively regulating the YAP-TEAD transcriptional complex. Cell Res. 2014; 24:331-43.

42. Jiao S, Wang H, Shi Z, Dong A, Zhang W, Song X, He F, Wang Y, Zhang Z, Wang W, Wang X, Guo T, Li P, et al. A peptide mimicking VGLL4 function acts as a YAP antagonist therapy against gastric cancer. Cancer Cell. $2014 ; 25: 166-80$.
43. Qiao Y, Lin SJ, Chen Y, Voon DC, Zhu F, Chuang LS, Wang T, Tan P, Lee SC, Yeoh KG, Sudol M, Ito Y. RUNX3 is a novel negative regulator of oncogenic TEAD-YAP complex in gastric cancer. Oncogene. 2016; 35:2664-74. https://doi. org/10.1038/onc.2015.338.

44. Suzuki H, Itoh F, Toyota M, Kikuchi T, Kakiuchi H, Imai $\mathrm{K}$. Inactivation of the 14-3-3 sigma gene is associated with 5' CpG island hypermethylation in human cancers. Cancer Res. 2000; 60:4353-57.

45. Urano T, Saito T, Tsukui T, Fujita M, Hosoi T, Muramatsu M, Ouchi Y, Inoue S. Efp targets 14-3-3 sigma for proteolysis and promotes breast tumour growth. Nature. 2002; 417:871-75.

46. Urano T, Takahashi S, Suzuki T, Fujimura T, Fujita M, Kumagai J, Horie-Inoue K, Sasano H, Kitamura T, Ouchi Y, Inoue S. 14-3-3sigma is down-regulated in human prostate cancer. Biochem Biophys Res Commun. 2004; 319:795-800.

47. Zhang Y, Li Y, Lin C, Ding J, Liao G, Tang B. Aberrant upregulation of 14-3-3 $\sigma$ and EZH2 expression serves as an inferior prognostic biomarker for hepatocellular carcinoma. PLoS One. 2014; 9:e107251.

48. Li Z, Liu JY, Zhang JT. 14-3-3sigma, the double-edged sword of human cancers. Am J Transl Res. 2009; 1:326-40.

49. Matta A, Siu KW, Ralhan R. 14-3-3 zeta as novel molecular target for cancer therapy. Expert Opin Ther Targets. 2012; 16:515-23.

50. Zhang X, Wang W, Wang $\mathrm{H}$, Wang $\mathrm{MH}, \mathrm{Xu} \mathrm{W}$, Zhang R. Identification of ribosomal protein S25 (RPS25)MDM2-p53 regulatory feedback loop. Oncogene. 2013; 32:2782-91. 